\title{
Performance of Two 18-Story Steel Moment-Frame Buildings in Southern California During Two Large Simulated San Andreas Earthquakes
}

\author{
Swaminathan Krishnan, ${ }^{\text {a) }}$ M.EERI, Chen Ji, ${ }^{\text {b) }}$ Dimitri Komatitsch, ${ }^{\text {c) }}$ \\ and Jeroen Tromp ${ }^{\text {a) }}$
}

\begin{abstract}
Using state-of-the-art computational tools in seismology and structural engineering, validated using data from the $\mathrm{M}_{\mathrm{w}}=6.7$ January 1994 Northridge earthquake, we determine the damage to two 18-story steel moment-frame buildings, one existing and one new, located in southern California due to ground motions from two hypothetical magnitude 7.9 earthquakes on the San Andreas Fault. The new building has the same configuration as the existing building but has been redesigned to current building code standards. Two cases are considered: rupture initiating at Parkfield and propagating from north to south, and rupture propagating from south to north and terminating at Parkfield. Severe damage occurs in these buildings at many locations in the region in the north-to-south rupture scenario. Peak velocities of $1 \mathrm{~m} \cdot \mathrm{s}^{-1}$ and $2 \mathrm{~m} . \mathrm{s}^{-1}$ occur in the Los Angeles Basin and San Fernando Valley, respectively, while the corresponding peak displacements are about $1 \mathrm{~m}$ and $2 \mathrm{~m}$, respectively. Peak interstory drifts in the two buildings exceed 0.10 and 0.06 in many areas of the San Fernando Valley and the Los Angeles Basin, respectively. The redesigned building performs significantly better than the existing building; however, its improved design based on the 1997 Uniform Building Code is still not adequate to prevent serious damage. The results from the south-to-north scenario are not as alarming, although damage is serious enough to cause significant business interruption and compromise life safety.

[DOI: 10.1193/1.2360698]
\end{abstract}

\section{INTRODUCTION}

The last major earthquake on the southern half of the San Andreas Fault was the Fort Tejon earthquake that occurred on 9 January 1857 (magnitude originally estimated to be 7.9 by Sieh 1978 , but subsequently upgraded to approximately 8.25 by the U.S. Geological Survey). This event was preceded by two estimated-magnitude 7.0 earthquakes on 8 and 21 December 1812. The 1857 event involved several meters of right lateral slip along the south-central reach of the fault and was widely felt (Sieh 1978). A majority of

\footnotetext{
a) Seismological Laboratory, California Institute of Technology, MS 252-21, Pasadena, CA 91125

b) Department of Geological Sciences, University of California, Santa Barbara, CA 93106

c) Department of Geophysical Modeling and Imaging, CNRS UMR 5212 and Magique 3D INRIA Futurs,

University of Pau, 64013 Pau Cedex, France
} 
reports indicate that the duration of shaking was between one and three minutes. Based on paleoseismological evidence, Sieh (1978) reconstructed the slip distribution along the fault for this event. The rupture initiated at Cholame about $25 \mathrm{~km}$ south of Parkfield in central California, grew to a peak slip of about $9.5 \mathrm{~m}$ at Wallace Creek (about $67 \mathrm{~km}$ from Cholame), and propagated south past Wrightwood in southern California for a total distance of about $330 \mathrm{~km}$. Newspaper accounts following the earthquake point to longperiod, large-amplitude, long-duration ground shaking in the Los Angeles Basin and the San Fernando Valley (Agnew and Sieh 1978, Meltzner and Wald 1998).

According to Weldon et al. (2005), even though the current 148-years hiatus in activity on the San Andreas Fault is not exceptional (although no lull in the past 1,600 years appears to have lasted more than about 200 years), when the current hiatus ends a substantial portion of the fault is likely to break, either as a single long rupture or, less likely, as a series of overlapping ruptures over a short time interval. The potential for a large earthquake with a large amount of slip on the San Andreas Fault exists. In order to prepare for this eventuality, it is critical to quantify the effects of such a scenario. In the absence of data, the only option is to use computer simulations for this purpose.

Seismologists have created 3-D Earth models (Magistrale et al. 1996, Magistrale et al. 2000, Kohler et al. 2003, Süss and Shaw 2003) of seismic wave speeds and density, and thanks to the advent of parallel computing now have the ability to study 3-D global and regional seismic wave propagation using approaches based on Finite Element and Finite Difference methods. Various research groups have simulated ground motions from earthquakes on faults in southern California (Heaton et al. 1995, Olsen et al. 1995, Graves 1998, Komatitsch et al. 2004, Liu et al. 2004), and some have studied the 2-D response of tall buildings under these ground motions (Hall et al. 1995, Hall 1998).

Meanwhile, the field of structural engineering has experienced its own renaissance. The effort by the Structural Engineers Association of California, Applied Technology Council, and California Universities for Research in Earthquake Engineering (SAC $1995 \mathrm{a}, \mathrm{b}, \mathrm{c})$ to understand the causes of damage to moment-frame buildings during the $\mathrm{M}_{\mathrm{w}}=6.7$ January 1994 Northridge earthquake in southern California has given a huge boost to computationally modeling damage in steel buildings. Many tools have been developed in recent years to perform 3-D nonlinear damage analyses of buildings using three-component ground motions (Lobo 1994, Powell and Campbell 1994, Prakash et al. 1994, Kunnath 1995, El-Tawil and Deierlein 1996, Lobo et al. 1998, Filippou and Romero 1998, Carlson 1999, Krishnan 2003a, Mazzoni et al. 2005).

With computational tools in seismology and structural engineering becoming more accurate, reliable, and versatile, it is a natural progression to bring the two together in the form of end-to-end simulations to address the risk posed to engineered structures. The primary objective of this study is to estimate numerically the damage that would occur in two 18-story steel moment-frame buildings in southern California from large earthquakes on the San Andreas Fault. The fact that this particular type of building has been selected for this study does not necessarily mean that this building type is the most vulnerable; in fact, it probably is not. There are thousands of nonductile concrete buildings that are at greater risk. However, this is a prototype study, and in a study such as this it 


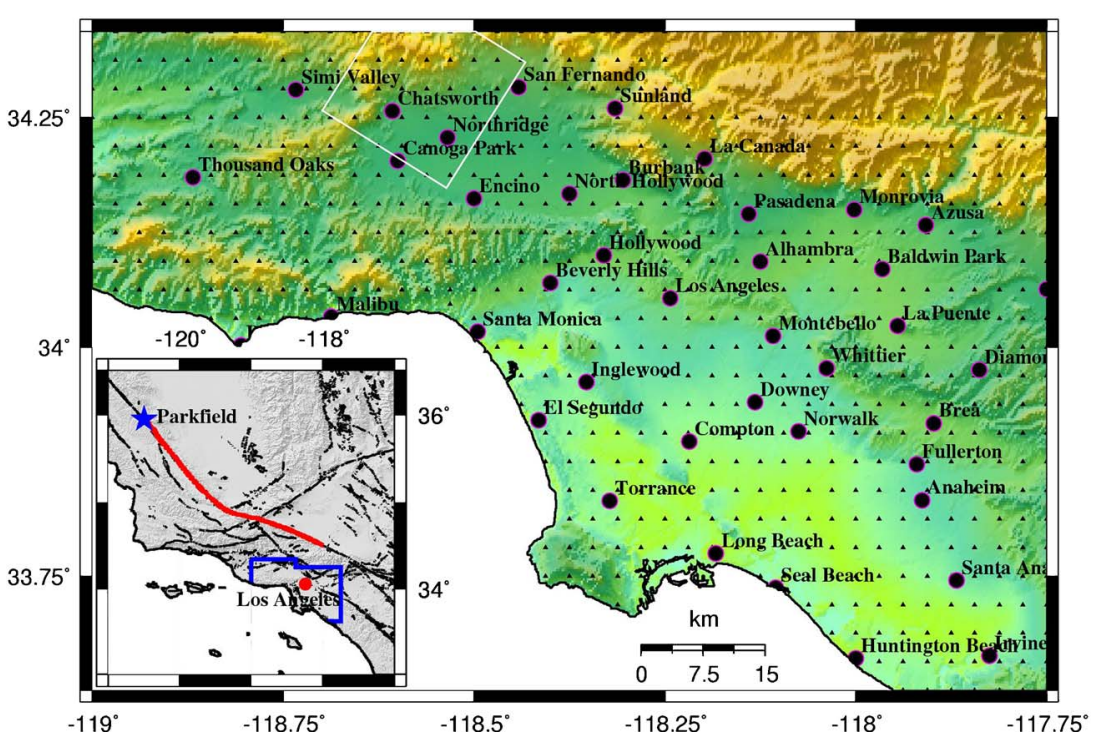

Figure 1. Geographical scope of the simulation (The color scheme reflects topography, with green denoting low elevation and yellow denoting mountains): The solid black triangles represent the 636 sites at which seismograms are computed and buildings are analyzed. The white box is the surface projection of the Northridge earthquake fault. The red line in the inset is the trace of the hypothetical 290-km rupture of the San Andreas Fault that is the primary focus of this study. The area enclosed by the blue polygon denotes the region covered by the 636 sites.

is important to target buildings that have already been investigated in detail, and whose behavior is well understood, so that a proof-of-concept can be established. Steel moment-frame buildings have been studied extensively since the Northridge earthquake, so this building type is a natural choice for this study. The regions of interest are the San Fernando Valley and the Los Angeles Basin. It was decided to divide the entire region into a uniformly spaced grid (with a spacing of $1 / 32$ of a degree or approximately $3.5 \mathrm{~km}$ each way) consisting of 636 sites shown by solid triangles in Figure 1 . The strategy was to place structural models of the two buildings at each of these sites on the grid and compute their response under ground motion from the two scenario earthquakes. The results are presented in the form of damage/drift performance maps.

Two scenarios involving the rupture of a 290-km segment of the San Andreas Fault are considered in this study. The first scenario consists of rupture initiating at Parkfield in central California and propagating in a southeasterly direction, with slip increasing gradually from Parkfield to a maximum value just northwest of the region of interest and dropping off abruptly to zero (Figure 1, inset). This slip distribution is derived from a finite-source inversion of the 3 November 2002, magnitude 7.9 Denali earthquake in Alaska ( $\mathrm{Ji}$ et al. 2003). The second scenario consists of the same source but reversed in direction, with the rupture initiating just north of the region of interest and terminating 
at Parkfield, and the peak slip occurring close to Parkfield. These two scenarios were specifically chosen to illustrate the effects of directivity and slip distribution on the computed ground motions.

Two buildings are considered in this study. The index structure is an existing 18story steel moment-frame building located on Canoga Avenue in Woodland Hills that experienced significant damage (moment-frame connection fractures) during the 1994 Northridge earthquake. The second building is similar to the index structure, but the structural system (i.e., the lateral force-resisting system) has been redesigned according to the 1997 Uniform Building Code (UBC 97) (ICBO 1997). The fundamental difference between the two structures is that the new building has been designed for larger earthquake forces (accounting for near-source effects) and stringent redundancy requirements in the lateral force-resisting system. This leads to significantly different dynamic characteristics. In general, the redesigned building can be expected to perform better than the existing building in the event of an earthquake. The description of the two structures and a detailed comparison in terms of their dynamic properties, static strength, and ductility are presented in the next few sections.

\section{EXISTING BUILDING}

The existing building considered in this study is a modern 18-story welded steel moment-frame building located within five miles of the epicenter of the 1994 Northridge earthquake. It was designed in 1984 according to the lateral force requirements of the 1982 Uniform Building Code (ICBO 1982) and construction was completed in 1986-87. It has 17 office stories above ground and a mechanical penthouse on top (Figure 2). There is a single basement. The height of the building above ground is $75.7 \mathrm{~m}\left(248^{\prime} 4^{\prime \prime}\right)$ with a typical story height of $3.96 \mathrm{~m}\left(13^{\prime} 0^{\prime \prime}\right)$ and taller $1^{\text {st }}, 17^{\text {th }}$, and penthouse stories. The plan configuration of the building is fairly uniform over its height. The lateral force-resisting system consists of two-bay welded steel moment frames, two apiece in either principal direction of the building. There are a few setbacks in the building that do not affect the lateral force-resisting system significantly. The east, west, and south moment frames lie on the perimeter of the building, while the north frame is located one bay inside of the perimeter. This gives rise to some torsional eccentricity. Many moment-frame beam-column connections in the building fractured during the Northridge earthquake, and the building has been extensively investigated since then by many engineering research groups (SAC 1995b, Carlson 1999). Figure 2a shows an isometric view of a structural model of the building. A typical floor plan is given in Figure 2c. Detailed floor plans, beam and column sizes, and gravity, wind, and seismic loading criteria are given in Krishnan et al. (2005). A36 steel with nominal yield strength of $248.29 \mathrm{MPa}$ (36 ksi) is used for all beams, while A572 Grade 50 steel with nominal yield strength of $344.85 \mathrm{MPa}(50 \mathrm{ksi})$ is used for all columns. The floors consist of lightweight concrete slab on metal deck supported by steel beams and girders framing into gravity and moment-frame columns.

The computed natural periods and the modal directions for the existing building (EB1) are given in Table 1. These are based on the assumption that live load does not contribute to the seismic mass (UBC 97 guideline). The modal direction factors identify 


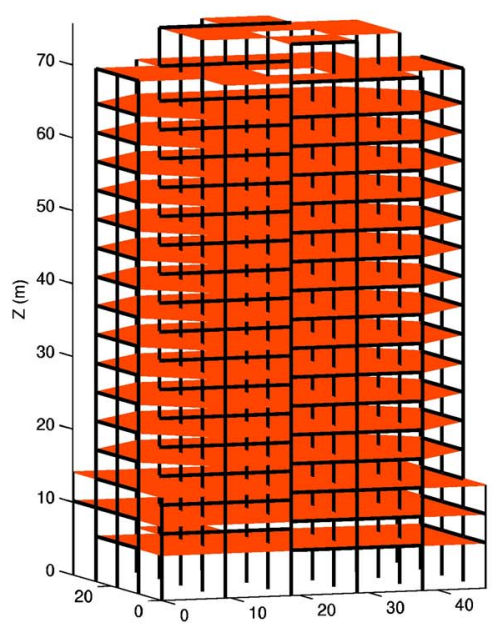

$Y(m)$

(a)

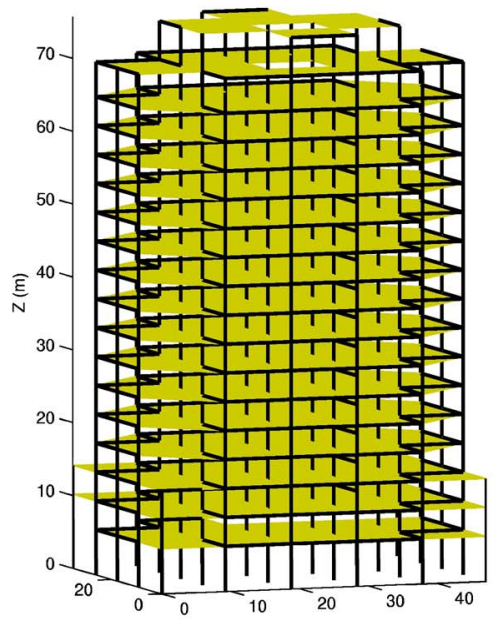

(b)

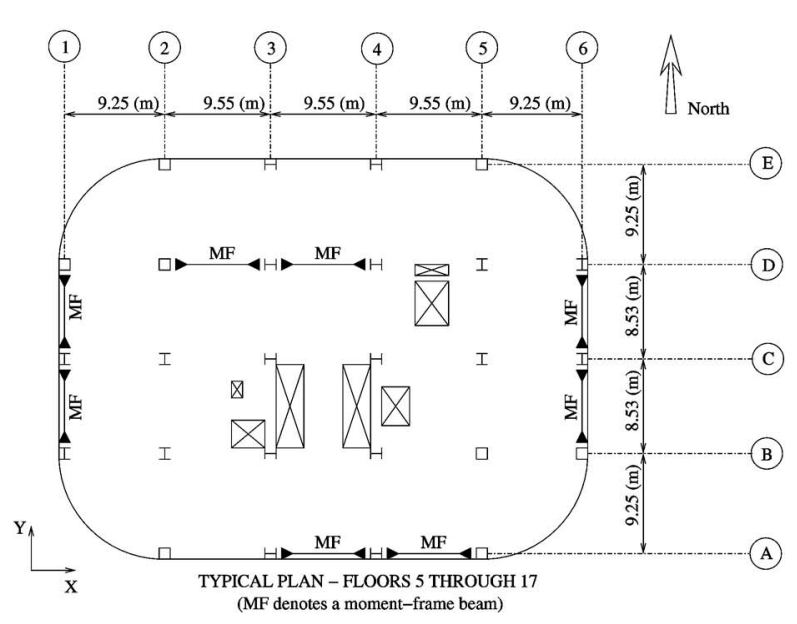

(c)

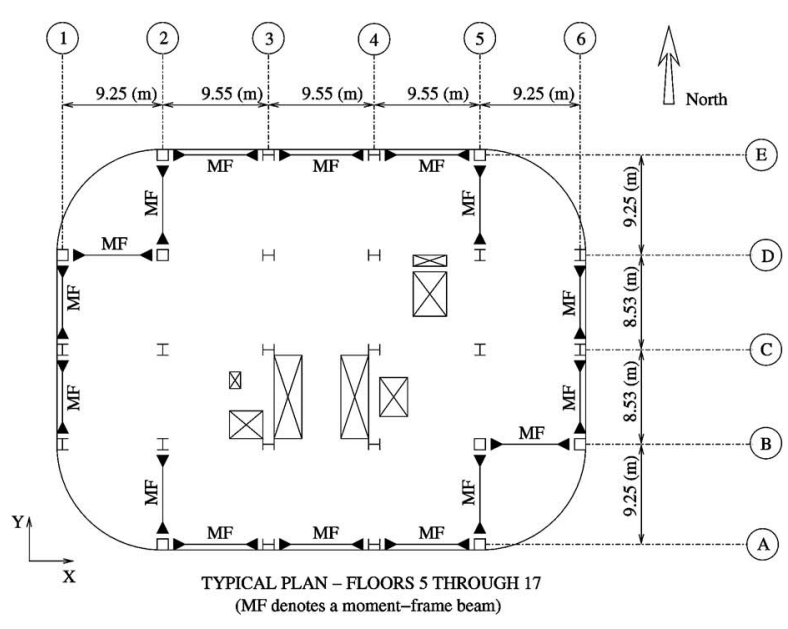

(d)

Figure 2. Structural models of the two buildings under study. (a) Isometric view of the existing building (designed using the 1982 Uniform Building Code). (b) Isometric view of the new building (redesigned using the 1997 Uniform Building Code). (c) Plan view of a typical floor of the existing building showing the location of columns and moment-frame (MF) beams. (d) Plan view of a typical floor of the redesigned (new) building showing the location of columns and moment-frame beams. Note the greater number of moment-frame bays in the redesigned building. 
Table 1. Natural periods and modal directions (first three modes) of the buildings

\begin{tabular}{cccccc}
\hline \hline \multirow{2}{*}{ Building ID } & & \multicolumn{3}{c}{ Modal Direction Factors } \\
\cline { 4 - 6 } & Mode Number & Period $(\mathrm{s})$ & X-Translation & Y-Translation & Z-Rotation \\
\hline \multirow{2}{*}{ EB1 } & 1 & 4.43 & 97.86 & 0.10 & 2.04 \\
& 2 & 4.22 & 0.10 & 99.89 & 0.01 \\
& 3 & 2.47 & 2.06 & 0.03 & 97.91 \\
\multirow{2}{*}{ EB1R } & 1 & 3.72 & 47.24 & 52.72 & 0.04 \\
& 2 & 3.51 & 52.71 & 47.27 & 0.02 \\
& 3 & 2.24 & 0.08 & 0.01 & 99.91 \\
\hline \hline
\end{tabular}

the predominant direction of excitation associated with each of the modes. The factors are percentages associated with the X- and Y-translational, and Z-rotational directions (Krishnan et al. 2005).

\section{PERFORMANCE OF THE EXISTING BUILDING DURING THE 1994 NORTHRIDGE EARTHQUAKE}

Following the Northridge earthquake, problems associated with the alignment of elevators prompted a survey that evaluated the plumbness of the existing building. The survey indicated that the building was leaning 6 in. to the north at roof level. A damage investigation of the building revealed fractures in 29 out of the 154 beam bottom flangeto-column welds in the east and west moment-resisting frames (SAC 1995b). The investigation included visual inspection of all moment-frame beam bottom flange-to-column welds, and ultrasonic testing of 39 top flange-to-column welds and some bottom flangeto-column welds. The west moment frame had 23 weld fractures, while the east moment frame had 6 fractures. No weld fractures were observed in the north and south moment frames. No top flange weld-fractures were observed in any of the moment frames. All observed fractures were visible from the top of the bottom flange. The fractures included cracks through the weld, cracks at the back of the weld adjacent to the column flange, and cracks that went into the column flange and exited the column flange above the weld. All weld fractures seemed to have initiated from the root of the full penetration welds.

There was a three-component SMA-1 accelerograph on the $18^{\text {th }}$ floor of the building that recorded the floor acceleration (Darragh et al. 1994). Unfortunately, the closest freefield seismometer was the Oxnard Boulevard (WHOX) station in Woodland Hills, about half a mile away from the building. Nevertheless, the building model was analyzed for shaking from the recorded WHOX data (Darragh et al. 1994) in order to validate the numerical technique that is subsequently used for the San Andreas earthquake scenario simulation. This nonlinear damage analysis of the structure was performed using the program FRAME3D (Krishnan 2003a, http://www.frame3d.caltech.edu). FRAME3D utilizes a Newton-Raphson iteration strategy applied to an implicit Newmark time integration scheme to solve the nonlinear equations of motion at each time step. It incorpo- 
rates geometric nonlinearity, which enables the modeling of the global stability of the building, accounting for P- $\Delta$ effects accurately. The moment-frame beams and columns are modeled using elastofiber elements that consist of three segments, two nonlinear end segments that are subdivided in the cross-section into a number of fibers, and an interior elastic segment (Krishnan and Hall 2006b). The beam-to-column joints are modeled in three dimensions using FRAME3D panel zone elements while the gravity columns are modeled using plastic hinge elements (Krishnan and Hall 2006a). These elements have been shown to simulate damage accurately and efficiently (Krishnan 2003b).

Material nonlinearity resulting in flexural yielding, strain-hardening and ultimately rupturing of steel at the ends of beams and columns, and shear yielding in the joints (panel-zones) is included. The fracture mode of failure is included in connections; however, local flange buckling in beams and columns is not. It is assumed that a fiber that is fractured cannot resist tension but, upon contact, can start resisting compression again. Column splices can be incorporated into the model but are excluded in this study. Floorframing beams with shear connections used to support gravity loads are not modeled. Their contribution to the strength and stiffness of the building may not be negligible. Soil-structure interaction (SSI) (e.g., Stewart et al. 1998, Trifunac et al. 2001a) is not included in the analyses because the required soil information pertaining to each site is not available. Furthermore, to the authors' knowledge, software capable of handling nonlinear dynamic soil-structure interaction in an efficient manner does not exist at this time. One of the few real-world examples of extensive SSI research is a 14-story reinforced concrete storage building in Hollywood constructed in 1925 (Serino 1989, Fenves and Serino 1990, Trifunac et al. 2001b). These studies indicate that the change in various structural response parameters in this building during the 1 October 1987, magnitude 5.9 Whittier Narrows earthquake due to SSI could have been up to $20 \%$. SSI is an active area of research and should be incorporated into future studies of this kind.

The computed displacements at the $18^{\text {th }}$ floor in the north-south (NS) and east-west (EW) directions are compared with the corresponding measured displacements in Figure 3 . While there is good agreement between the measured and the computed NS displacements, the same cannot be said about the EW displacements. Unfortunately, there is a great deal of uncertainty associated with this comparison. To start with, the ground motion used in the analysis was not recorded at the base of the building, but rather half a mile away. The instrument at the roof was maintained by the owner of the building and its reliability is therefore uncertain. There are several modeling limitations also: rocking of the building about its base is not included in the fixed-base structural model. This rocking mode could have contaminated the displacement record measured at the penthouse level and this could explain the apparent lengthening of the period (as seen in the measured record), although the period lengthening can also be attributed to damage in the building. The observed cycles in the displacement history could be attributed to a combination of translational and rocking modes instead of purely the translational mode. The greater attenuation of the measured displacement may be the result of an increase in nonhysteretic damping due to damage accumulation. Note that while hysteretic damping 


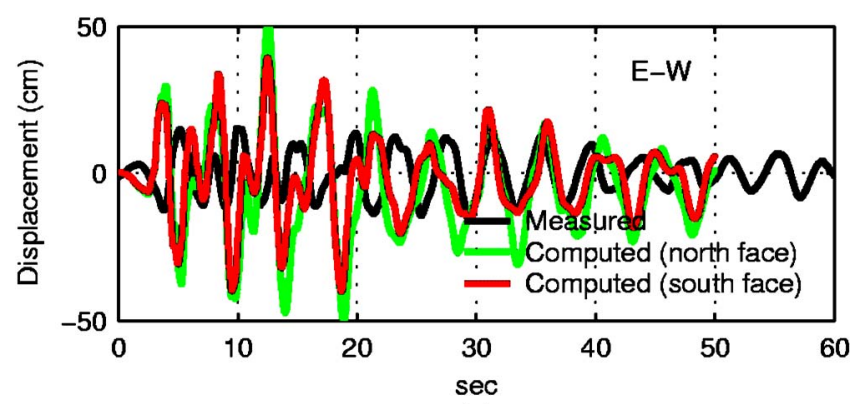

(a)

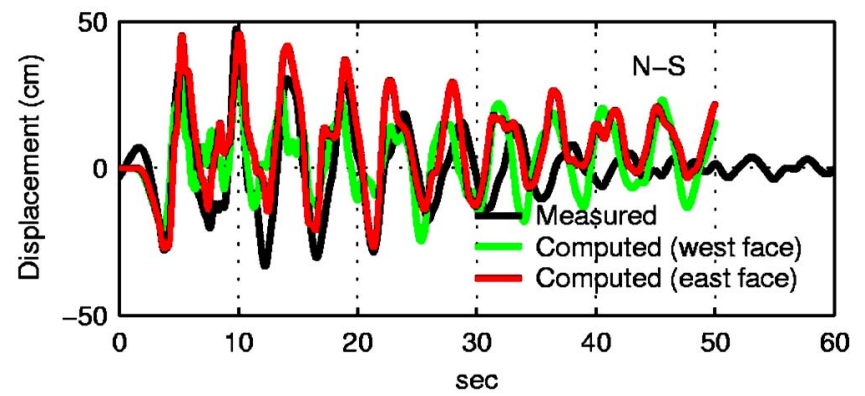

(b)

Figure 3. Validation of the structural modeling procedure using Northridge earthquake dataanalysis of existing building in Woodland Hills subjected to the three-component Oxnard Boulevard acceleration record (WHOX station located 0.5 mile from the building): Measured 18th floor N-S (a) and E-W (b) displacements versus corresponding computed displacements.

is modeled accurately in a nonlinear fashion in the structural model, nonhysteretic supplemental damping is considered to be viscous and linear, and as damage accumulates, it does not increase correspondingly.

The location of fractures in the four moment frames in the building from the analyses is compared with the location of observed fractures in the building in Figure 4. Since all the fractures were observed in the bottom flange weld (SAC 1995b), for the purposes of this analysis, the fracture strain in all the welds in the building model, except the beam bottom-flange welds, was taken to be far greater than the steel fiber rupture strain. The fracture strain for the beam bottom-flange welds was varied and the structural analysis was carried out repeatedly until the total number of weld fractures in the model matched the observed number of fractures in the building following the Northridge earthquake. A beam bottom-flange weld fracture strain of 1.05 times the yield strain, $\epsilon_{\mathrm{y}}$, results in a total of 29 weld fractures in the analysis, which is the same number that was observed in the field. The fracture distribution in the various moment frames of the model is compared with that observed in the building in Figure 4. In both cases the fractures are confined to the NS moment frames. The majority of the fractures occur in the top third of the moment frames in both cases. However, while most fractures in the 


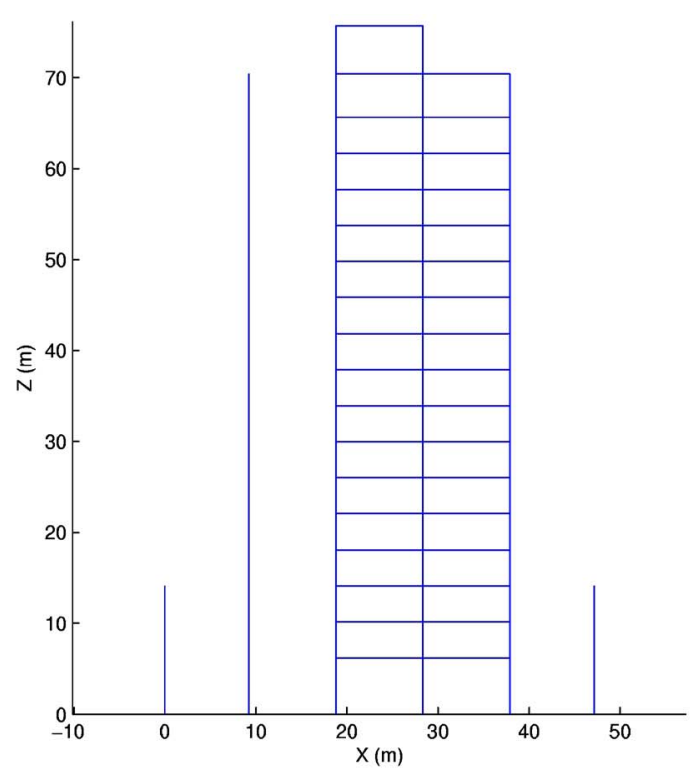

(a)

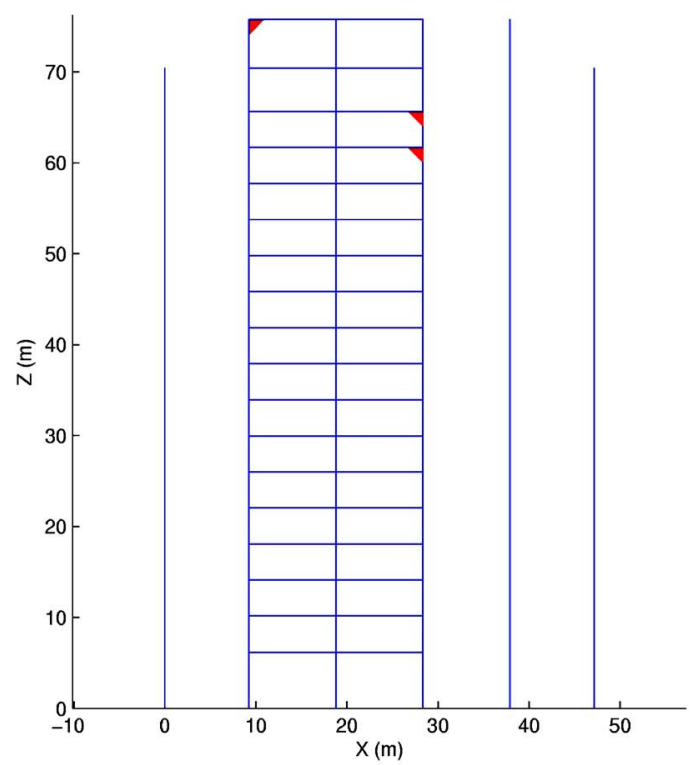

(b)

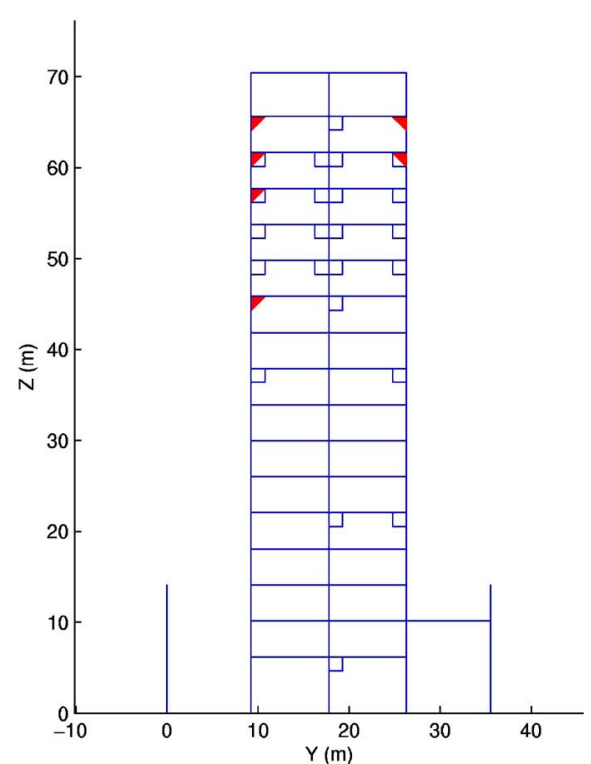

(c)

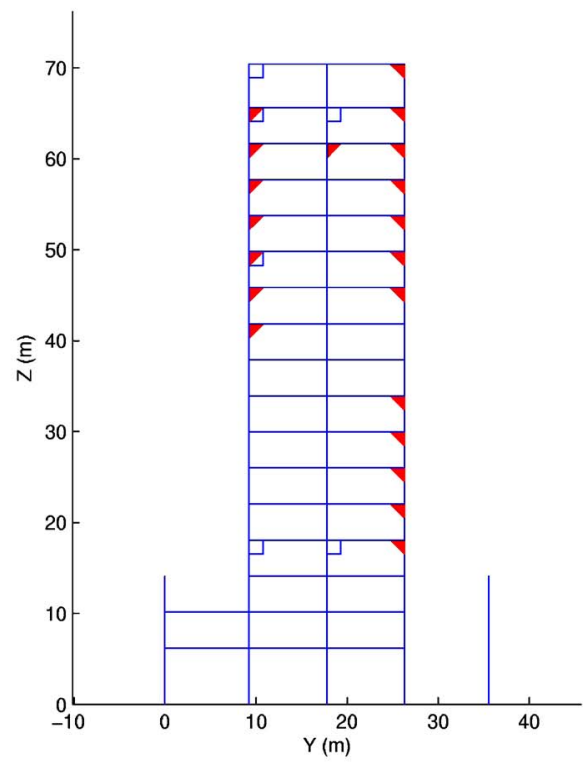

(d)

Figure 4. Analysis of the existing building subjected to the Oxnard Boulevard, Woodland Hills (WHOX seismic station located 0.5 mile from building) acceleration record from the Northridge earthquake-Observed connection fractures (squares) versus simulated fractures (solid triangles): (a) south moment frame (along grid A, east-west direction) of the building; (b) north moment frame (along grid D, east-west direction) of the building; (c) west moment frame (along grid 1, north-south direction) of the building; (d) east moment frame (along grid 6, north-south direction) of the building. 


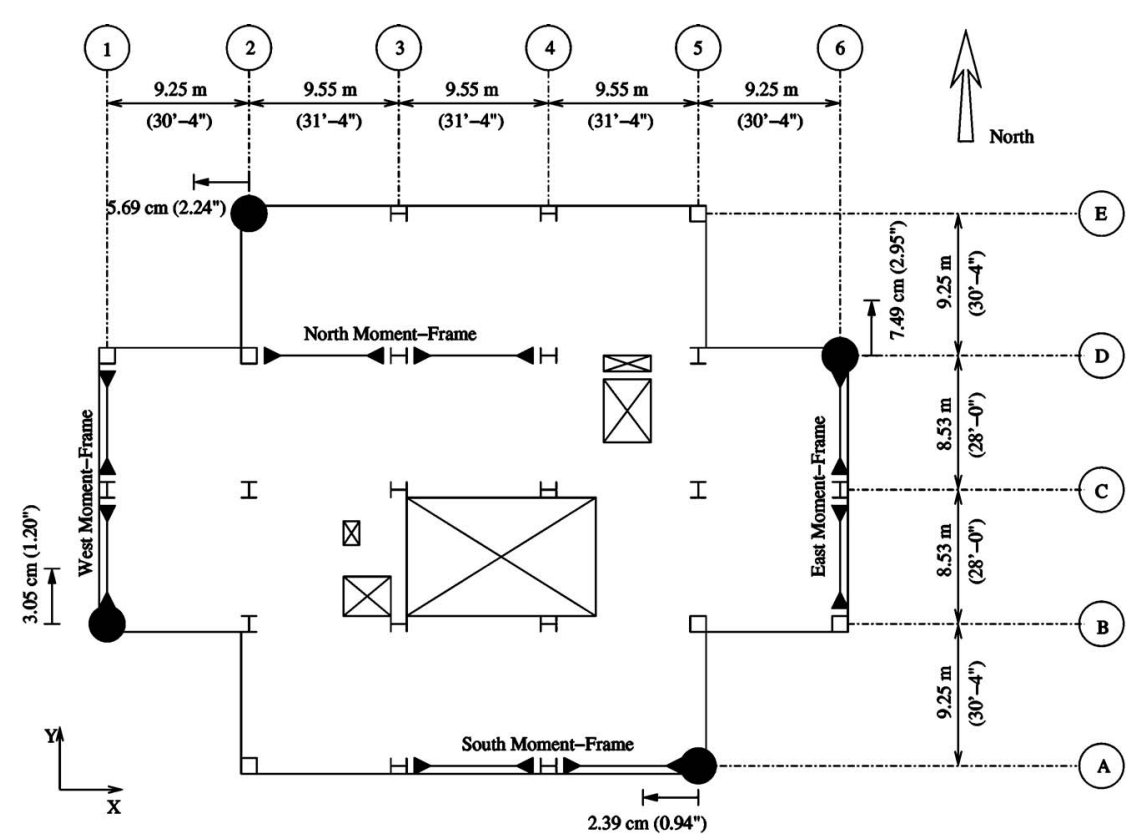

Figure 5. Permanent offsets of the four faces of the existing building model (penthouse plan shown) computed using the WHOX acceleration record from the Northridge earthquake.

building occurred in the west moment frame (23) with fewer fractures in the east moment frame (6), the opposite is true for the model with 6 fractures in the west moment frame and 20 fractures in the east moment frame. If the sign of the east component of the WHOX ground motion record is reversed, then the damage pattern in the model is similar to the observed pattern. However, the recording instrument was a threecomponent SMA-1 strong motion accelerograph for which an orientation reversal of one of the two horizontal components is possible only in conjunction with an orientation reversal of the other horizontal component. Yet another unexplained observation is that a twin building with the same configuration, design, and orientation had a very different damage pattern compared to the building considered here (based on personal communication with one of the authors of the SAC 1995b report). Unfortunately, the details of this building were not included in the report. In any case, the precise location of fractures in any building may be quite hard to predict as a result of the inherent random character of connection fractures owing to such unpredictable factors as variability in weld quality, yield strength of individual beams and columns, and other factors not directly accounted for in the model.

The permanent tilts of the four faces of the computational model are shown in Figure 5. Permanent tilt at a given location in the building is computed by taking the displacement time history at that location and lowpass-filtering it using a Butterworth filter with a corner period at $10 \mathrm{~s}$ and taking the average over the time window that has the mini- 
mum variance. The length of the time window was taken to be $5 \mathrm{~s}$. Note that this is the tilt in the building relative to the ground. Leaning of the building as a result of a tilt of the ground, or differential settlement in the structure foundation following the earthquake would not be captured by the structural model. Twisting of the model has resulted in a non-uniform pattern of permanent tilting of the four faces. The northeast corner has a net permanent offset of $3.7 \mathrm{in}$. in a northwesterly direction. Recall that the observed offset in the building was 6 in. to the north (SAC 1995b).

\section{REDESIGNED BUILDING}

There have been many improvements in building codes and construction practices since 1994, and buildings designed according to UBC 97 (ICBO 1997) are required to resist larger earthquake forces if located in regions close to major faults. Their lateral force-resisting systems are also required to be more redundant, which in the case of moment frames translates to a greater number of bays. In addition, the post-Northridge framing connections proposed in the wake of failures observed in the 1994 Northridge earthquake are likely to behave in a ductile fashion. The specifications developed by the Federal Emergency Management Agency (FEMA) for moment-frame construction strive to achieve this in the field (SAC 2000b). Thus new steel moment-frame buildings are expected to perform far better than existing buildings in large earthquakes, and it is of interest to study the performance of such buildings under the scenario earthquakes considered here. To this end, the existing 18-story building has been redesigned for $U B C 97$ requirements.

The gravity- and wind-loading criteria from the existing building were retained for the design of the new building. For the seismic static base-shear calculation, near-source factors were computed assuming a Type A seismic source at a distance of $5 \mathrm{~km}$ from the building; soil type $\mathrm{S}_{\mathrm{b}}$ was assumed as well (ICBO 1997). The stricter lateral force and redundancy requirements of $U B C 97$ led to a reconfiguration of the lateral system, resulting in a greater number of bays of moment frames in each direction (4 bays on each face of the building). A typical floor plan is given in Figure 2d. Detailed floor plans, beam and column sizes, and the gravity-, wind-, and seismic-loading criteria are given in Krishnan et al. (2005). Note that the moment frame that was located in the interior of the existing building on grid D has been moved to the perimeter (to grid E). The two-story space required at the lobby of the building precludes moment-frame beams on grid $\mathrm{E}$ at the second floor between grids $1-2,3-4$, and 4-5. This probably prompted the structural engineers of the existing building to move the frame to the interior of the building to grid D. But since the stiffness demand at the lower levels is not as high, it was concluded that the frame would be stiff enough with a single beam at the second floor on grid E. Box sections are used for the columns left unsupported laterally for two stories at E-1, E-4, E-5, and E-6, to keep the slenderness ratio governing the design within reasonable limits. ASTM A572 Grade 50 steel with nominal yield strength of $344.85 \mathrm{MPa}$ (50 ksi) is used for both beam and column sections, as well as for doubler plates that are provided to strengthen panel zones. 
The computed natural periods and the modal directions for the redesigned building (EB1R) are given in Table 1. Note that the redesigned building is far stiffer than the existing building.

\section{PUSHOVER ANALYSES OF EXISTING AND REDESIGNED BUILDINGS}

To quantify the actual strength and ductility (deformation potential) of the two buildings in the two principal directions, pushover analyses are performed in each direction. The building is subjected to a slow, ramped, horizontal ground acceleration that increases at a constant rate of $0.3 \mathrm{~g} /$ minute, and the building response is computed dynamically using FRAME3D. The structural model is identical to that used in the earthquake analyses except that masses for the horizontal degrees of freedom are recalculated such that their sum matches the total seismic-design mass, $\mathrm{W} / \mathrm{g}$, with a distribution that is proportional to the UBC 97 (ICBO 1997) seismic static design loads. Thus the lateral loads are essentially proportional to the horizontal seismic design forces over the height of the structure increasing with time at a slow rate. The ductility of the building can also be quantified in terms of its post-yield displacement capacity.

The results of the pushover analyses of both buildings are presented in Figure 6. The base shear in the direction of pushing is plotted as a percentage of the seismic weight of the building against the displacement at the $18^{\text {th }}$ floor (penthouse level) for the two models of the existing building that include fracture denoted by "EB1-FRAC-S" and "EB1FRAC-W" and fracture-excluded models of the existing and redesigned buildings denoted by "EB1-UNFRAC" and "EB1R-UNFRAC," respectively (Figures 6a and 6c). The seismic weights computed according to UBC 97 for the existing and new buildings are 12,689 metric tonnes (27,974 Kips) and 12,835 metric tonnes (28,297 Kips), respectively. The ultimate strength of the existing building model in the $x$ direction varies between $7.5 \%$ and $7.85 \%$ of its seismic weight for the three cases-FRAC-S, FRAC-W, and UNFRAC, while the ultimate strength of the redesigned building model in the $x$ direction is $9.5 \%$ of its seismic weight. Plotted in Figure $6 \mathrm{~b}$ are the base shear as a percentage of the seismic weight (solid lines) and the penthouse displacement (dashed lines) as a function of time for the $x$ direction pushover for each case. The penthouse lateral displacement at which the peak base shear is reached in the $x$ direction is about $1.73 \mathrm{~m}$ (68 in.) for both building models, which corresponds to an average inclination of $2.3 \%$ over the height. Both building models are stronger in the $y$ direction with ultimate strengths of about $8 \% \mathrm{~W}$ for the existing building and close to $10 \% \mathrm{~W}$ for the redesigned building. Plotted in Figure $6 \mathrm{~d}$ are the base shear as a percentage of the seismic weight (solid lines) and the penthouse displacement (dashed lines) as a function of time for the $y$ direction pushover for each case. The penthouse lateral displacement at which the peak base shear is reached in the $y$ direction is about $1.52 \mathrm{~m}$ (i.e., 60 in. or $2.0 \%$ average inclination) for the existing building model and $1.91 \mathrm{~m}$ (i.e., $75 \mathrm{in}$. or $2.5 \%$ average inclination) for the redesigned building model.

The FRAC-W model assumes a constant fracture strain of $0.9 \epsilon_{\mathrm{y}}$ (where $\epsilon_{\mathrm{y}}$ is the yield strain) for all the bottom fibers in the two nonlinear end segments of the elastofiber elements used to model the moment-frame beams (Krishnan and Hall 2006b). For fracture strain of the beam top flange and web fibers, the following probability distribution 


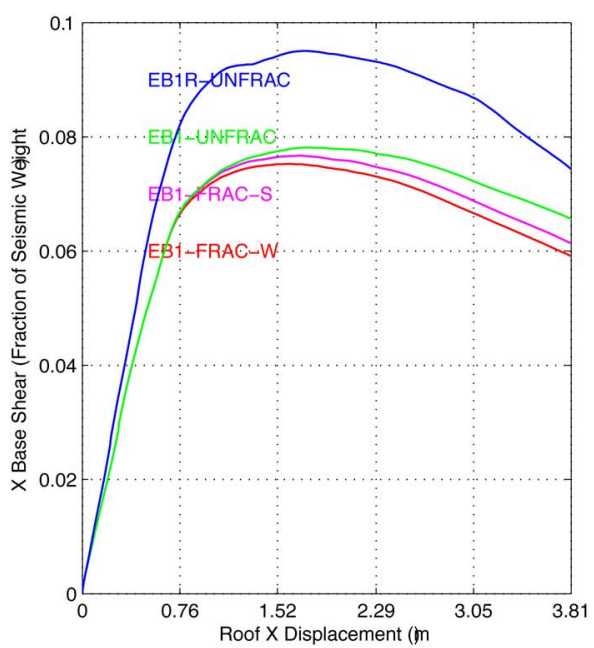

(a)

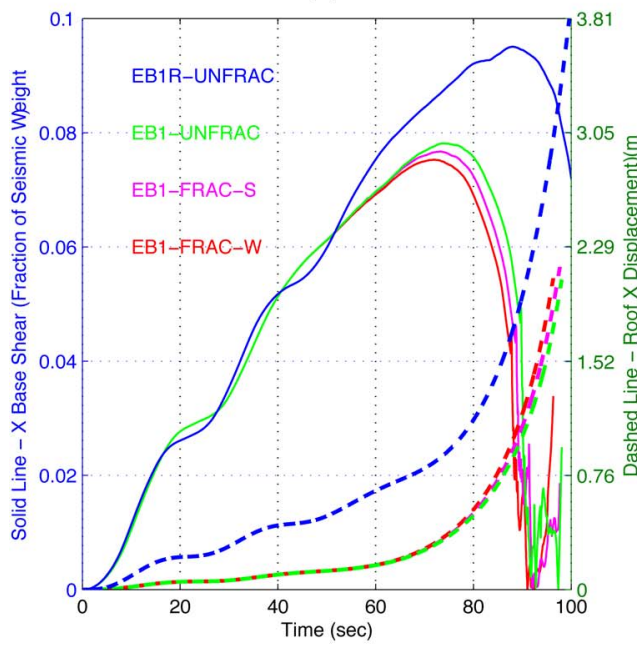

(b)

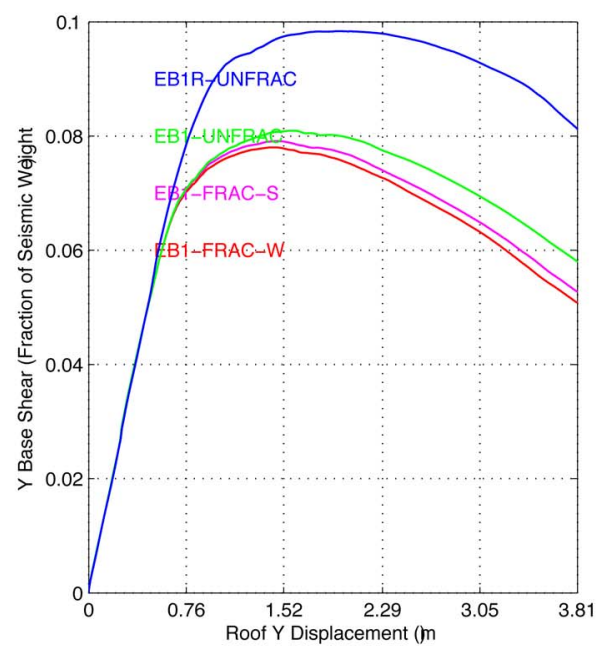

(c)

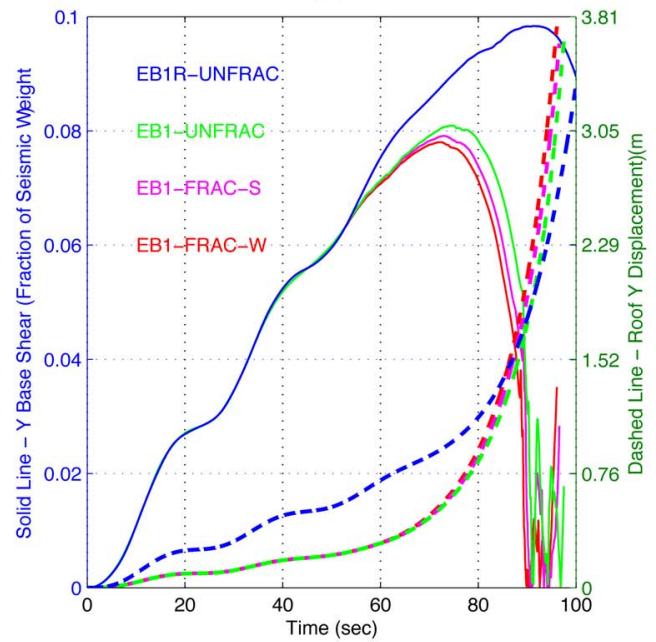

(d)

Figure 6. Pushover analyses of the existing (EB1) and the redesigned (EB1R) buildings: (a) $X$-direction pushover - roof displacement versus base shear. (b) $X$-direction pushover-base shear (solid lines) and roof displacements (dashed lines) as functions of time. (c) $Y$-direction pushover-roof displacement versus base shear. (d) $Y$-direction pushover-base shear (solid lines) and roof displacements (dashed lines) as functions of time. UNFRAC refers to a case in which the fracture mode of failure is not included. FRAC-S and FRAC-W refer to analyses with strong and weak fracture strain distribution assumptions, respectively, for the moment-frame beam bottom-flange fibers.

is assumed: $30 \%$ probability that the fracture strain is $10 \epsilon_{\mathrm{y}} ; 30 \%$ probability that it is 20 $\epsilon_{\mathrm{y}} ; 20 \%$ probability that it is $40 \epsilon_{\mathrm{y}}$; and $20 \%$ probability that it is $80 \epsilon_{\mathrm{y}}$. For each element 


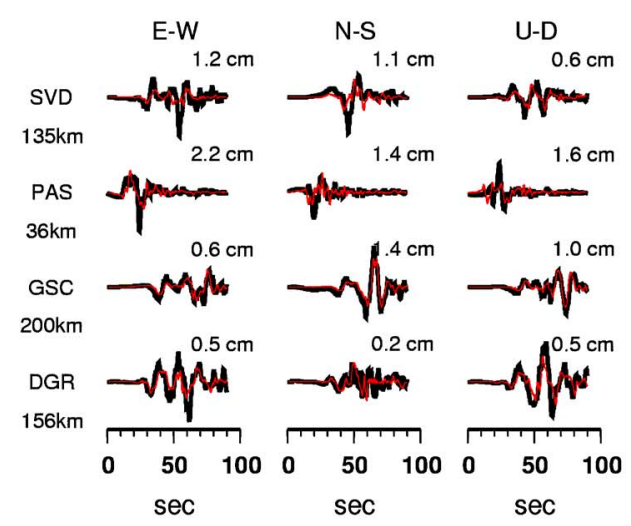

(a)

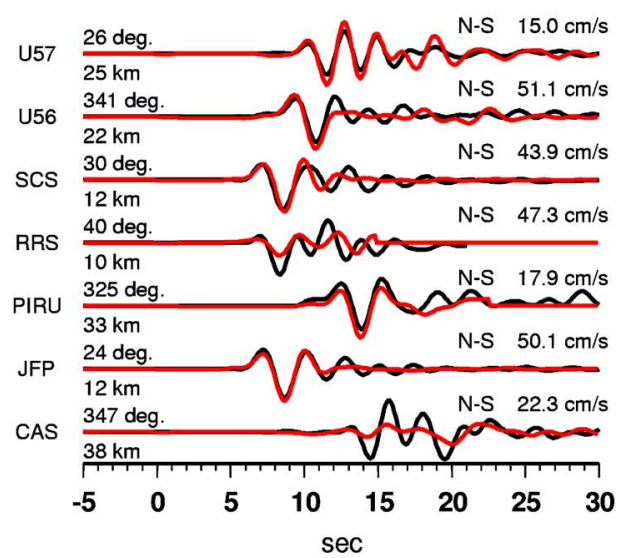

(b)

Figure 7. Numerical simulation of the Northridge earthquake: (a) Data (black) versus synthetic seismograms (red) — distant stations, and (b) data versus synthetic seismograms - nearby stations north of the rupture. Station identification labels, epicentral distances, and orientations are given. The waveform peak velocities and displacements are also listed.

a random number is generated, and based on its value a fracture strain consistent with this probability distribution is assigned to each fiber of the top flange and the web. For column flange and web fibers, it is assumed that the fracture strains are far greater than the rupture strain, thus precluding the occurrence of fractures.

The FRAC-S model makes the same assumptions with regard to the fracture strain as the FRAC-W model, except that the fracture strain for the bottom-flange fibers of the moment-frame beams is not constant but determined based on the following probability distribution: $20 \%$ probability that the fracture strain is $0.9 \epsilon_{\mathrm{y}} ; 20 \%$ probability that it is $2 \epsilon_{\mathrm{y}} ; 20 \%$ probability that it is $5 \epsilon_{\mathrm{y}} ; 20 \%$ probability that it is $15 \epsilon_{\mathrm{y}}$; and $20 \%$ probability that it is $40 \epsilon_{\mathrm{y}}$.

\section{NUMERICAL SIMULATION OF GROUND MOTION}

The numerical simulations of ground motion, accounting for 3-D variations of seismic wave speeds and density, topography, and bathymetry (the large model of the Los Angeles region includes a part of the Pacific Ocean, hence the need for bathymetry), and seismic attenuation, are carried out using our open-source seismic wave propagation package SPECFEM3D (http://www.geodynamics.org). The methodology adopted therein has been shown to reliably model ground motion in the Los Angeles region down to a shortest period of approximately $2 \mathrm{~s}$ (Komatitsch et al. 2004, Liu et al. 2004). Here two validation exercises are performed.

First, a simulation of the 17 January 1994, magnitude 6.7 Northridge earthquake is carried out and the synthetic seismograms are compared with measured records at a suite of stations, some located far away from the fault (Figure 7a) and some near the 
fault (Figure 7b). The good match in the waveforms in terms of amplitudes and frequency content illustrates the validity of using this approach to simulate ground motions with periods greater than $2 \mathrm{~s}$ in the Los Angeles Basin (note that both the simulated and the measured records shown in these figures are lowpass-filtered using a Butterworth filter with a corner period at $2 \mathrm{~s}$ ).

Second, since in general the response of a structure depends on the entire frequency band of ground motion, the acceptability of using the band-limited simulated ground motion records for the analysis of the two 18-story buildings considered here needs to be demonstrated. To accomplish this, we performed nonlinear analyses of the existing and redesigned buildings subject to 13 three-component filtered and unfiltered records from the 21 September 1999, magnitude 7.7 Chi-Chi earthquake in Taiwan, and the 25 September 2003, magnitude 8.3 Tokachi-Oki earthquake in Japan. Response spectra of the north and east components of these records, shown in Figures $8 \mathrm{a}$ and 8b, respectively, illustrate the wide range of intensities of the chosen ground motion. The results of the building analyses indicate that the response of both buildings when subjected to the filtered records is not significantly different from their corresponding response when subjected to the unfiltered records for all damage ranges. This can be seen clearly in plots of the peak drift ratio occurring in the two cases plotted against each other, Figure $8 \mathrm{c}$ for the existing building and Figure $8 \mathrm{~d}$ for the redesigned building, wherein most of the points closely follow the diagonal. This demonstrates that band-limited simulated ground motions can indeed be reliably used for the analysis of the two 18-story buildings considered in this study. Note that the colors used to plot the points in these figures correspond to those used to plot the response spectra in Figures 8a and 8b. Thus each point can be identified with the corresponding ground motion record.

A key limitation of the ground motion simulation methodology that requires serious consideration in future studies is that the top soil layer is not included in the Earth model due to lack of sufficient data as well as the complexity associated with taking into account low shear-wave velocities in the layer in the mesh used in the numerical technique. This typically softer layer may have the effect of significantly amplifying the ground motion (Haskell 1960, Anderson et al. 1996). Also, the simulations do not consider scattering of the wave field from city buildings (e.g., Clouteau and Aubry 2001).

\section{SAN ANDREAS SIMULATION: NORTH-TO-SOUTH RUPTURE}

For a San Andreas simulation it is critical to have a realistic source model (slip distribution as a function of time along the fault). On 3 November 2002, a magnitude 7.9 earthquake occurred on the vertical, right-lateral, Denali strike-slip fault system in Alaska, which is geometrically similar to the San Andreas Fault. For the simulation of the first scenario earthquake, the slip on the Denali fault system during the 2002 earthquake is mapped onto the San Andreas Fault, with the rupture initiating at Parkfield and progressing in a southeasterly direction over a distance of about $290 \mathrm{~km}$ (Figure 1 inset). The maximum depth of rupture is about $20 \mathrm{~km}$. The surface slip grows slowly to $7.4 \mathrm{~m}$ and drops off drastically towards the end of the rupture. The peak slip at depth is about $12 \mathrm{~m}$. To study the effects of directivity and spatial slip distribution on the basin ground 


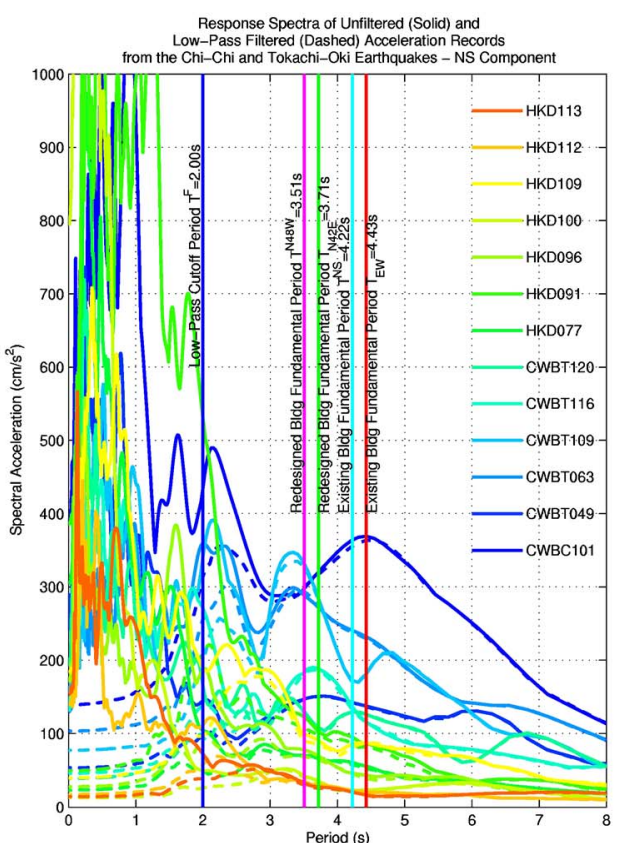

(a)

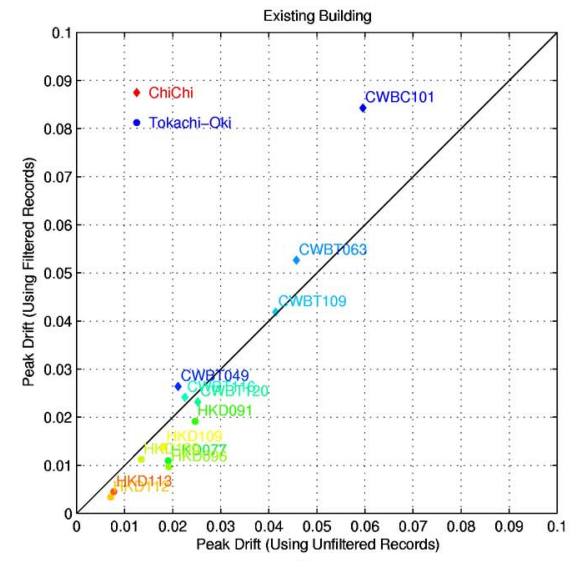

(c)

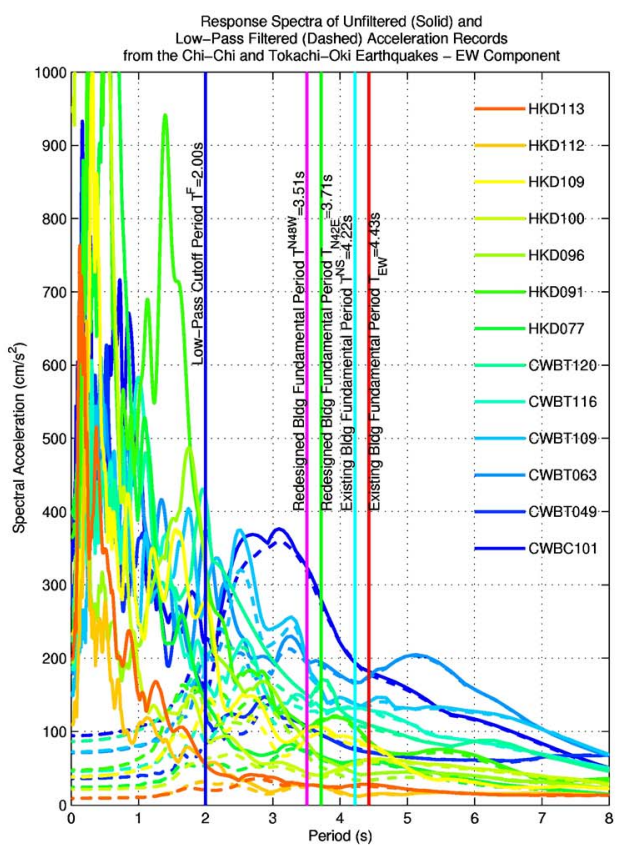

(b)

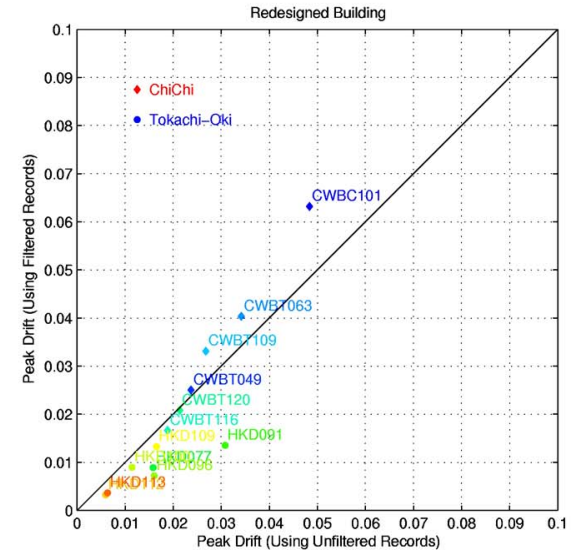

(d)

Figure 8. (a) and (b) Pseudo-acceleration response spectra of records from the $1999 \mathrm{M}_{\mathrm{w}} 7.7$ Chi-Chi, Taiwan, and the $2003 \mathrm{M}_{\mathrm{w}} 8.3$ Tokachi-Oki, Japan, earthquakes: Comparison of spectra of unfiltered (solid) and filtered (dashed) records. (c) Peak drifts observed in the existing building - analyses performed using filtered and unfiltered records. The color code is the same as that used in (a) and (b). (d) Peak drifts observed in the redesigned building - analyses using filtered and unfiltered records. The close alignment of all the points with the diagonal for all damage ranges indicates that the effect of higher-frequency ground motion (periods $<2 \mathrm{~s}$ ) on the response of the tall buildings considered in this study is not significant and can be safely ignored. 


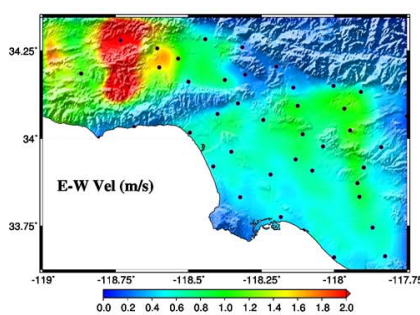

(a)

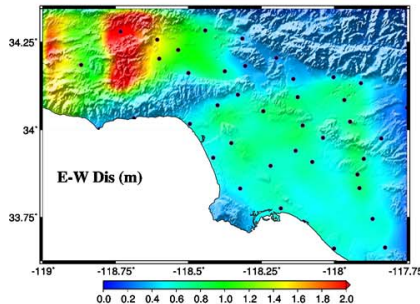

(b)

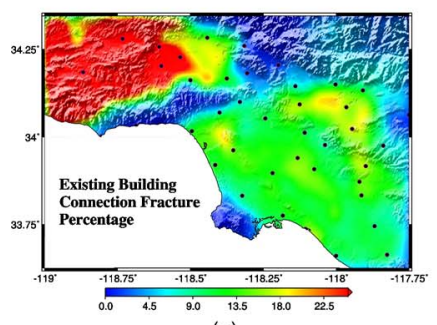

(c)

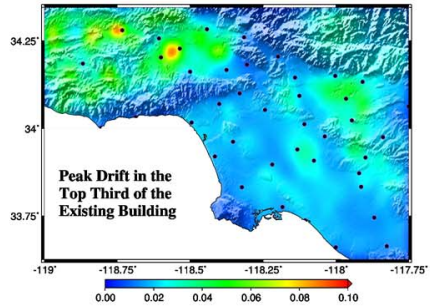

(d)

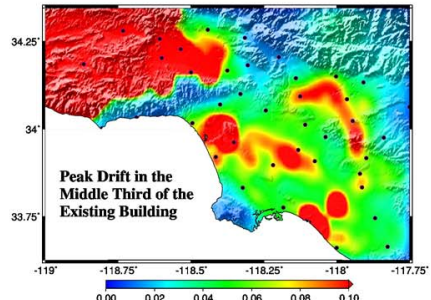

(e)

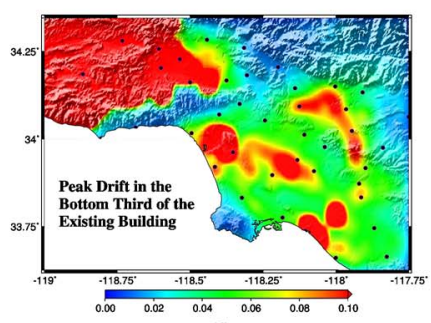

(f)

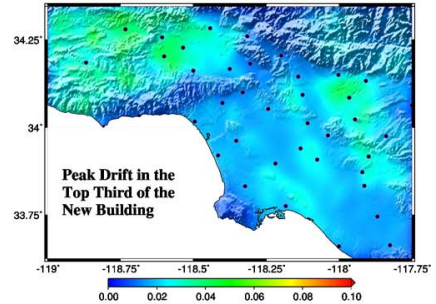

(g)

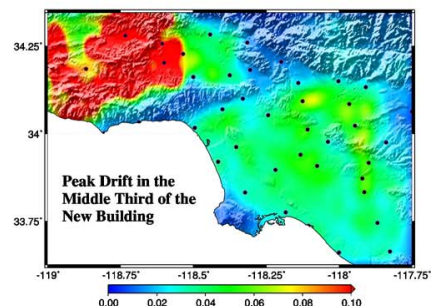

(h)

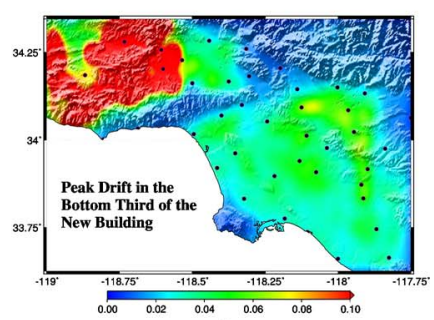

(i)

Figure 9. Ground shaking and building performance for a hypothetical $\mathrm{M}_{\mathrm{w}} 7.9$ earthquake (north-to-south rupture) on the San Andreas Fault: Shown are the peak ground velocity (a) and displacement (b) of synthetic seismograms lowpass-filtered with a corner period of $2 \mathrm{~s}$, the percentage of connections in the existing building where fractures occur out of 710 connections with the two ends of each moment-frame beam and column defined as connections (c), the peak interstory drift in the top (d), middle (e), and bottom third (f) of the existing building, and the corresponding peak drifts for the new building ( $\mathrm{g}, \mathrm{h}$, and i, respectively). Peak interstory drifts beyond 0.06 are indicative of severe damage, while drifts below 0.01 are indicative of minimal damage not requiring any significant repair.

motion, in the next section a second scenario is considered with rupture propagating from south-to-north and terminating at Parkfield, with the peak slip occurring close to Parkfield.

Using the spectral-element method (e.g., Komatitsch and Tromp 1999), seismograms are computed at each of the 636 analysis sites shown in Figure 1. Time histories with a time step of $9 \mathrm{~ms}$ are computed for a total duration of $270 \mathrm{~s}$, and lowpass-filtered using a Butterworth filter with a corner period at $2 \mathrm{~s}$. The filtered time histories at each analysis site are windowed to select only the portion that constitutes significant ground shak- 
ing up to a maximum duration of $70 \mathrm{~s}$. Maps of the east component (which happens to be the dominant component in the majority of locations, although the N-S component is stronger in the cities along the coast and in the area around Compton) of the peak velocity and displacement are shown in Figures 9a and 9b, respectively. The solid circles in these maps correspond to the cities shown in Figure 1. Regions that are closest to the fault trace experience the strongest shaking. Strong directivity dictated by the big bend in the San Andreas Fault leads to large peak velocities $\left(2 \mathrm{~m} . \mathrm{s}^{-1}\right)$ and displacements $(2 \mathrm{~m})$ in the San Fernando Valley. Going south from the San Gabriel mountains and the Hollywood hills into the Los Angeles Basin the peak velocities and displacements reduce to about $1 \mathrm{~m} \cdot \mathrm{s}^{-1}$ and $1 \mathrm{~m}$, respectively, although the Baldwin Park/La Puente region in the San Gabriel Valley, which is quite close to the location of rupture termination, experiences shaking with a peak velocity up to $1.2 \mathrm{~m} \cdot \mathrm{s}^{-1}$ and a peak displacement up to $1.1 \mathrm{~m}$. Even Orange County (especially the cities of Fullerton and Anaheim), which is located quite some distance from the fault (more than $50 \mathrm{~km}$ ), experiences strong shaking. The coastal cities (including Santa Monica, El Segundo, Long Beach, and Seal Beach) experience large-amplitude shaking for long durations.

Following the ground motion simulation, models of the existing and redesigned buildings are analyzed for the duly processed, simulated waveforms using FRAME3D. In each case the building $y$ direction is aligned with the geographical north direction. For the existing building we adopt the FRAC-S model which, as described previously, assumes two different probability distributions, one for the beam bottom flange, and the other for the beam top flange and web. The vulnerability of connections in the redesigned building to fracture, on the other hand, is assumed to have been eliminated, given the vast amount of corrective measures proposed by FEMA (SAC 2000b), and the UNFRAC model, described earlier, is adopted for this building. The peak interstory drift is the most reliable performance measure to evaluate structural performance. FEMA proposes peak interstory drift limits of $0.007,0.025$, and 0.05 , for the Immediate Occupancy (IO), Life Safety (LS), and Collapse Prevention (CP) performance levels, respectively, for existing buildings (ASCE 2000), and 0.01 and 0.06 for the IO and CP performance levels, respectively, for new buildings (SAC 2000a). These numbers were not intended to be hard criteria upon which performance would be judged. Nevertheless, in the absence of other criteria, they provide a basis for performance assessment.

Maps of the peak interstory drift that occurs in the top-third, middle-third, and bottom-third of the existing and redesigned building models are shown in Figures $9 \mathrm{~d}-9 \mathrm{f}$ and $9 \mathrm{~g}-9 \mathrm{i}$, respectively. The first observation is that the redesigned building performs better than the existing building, which reflects the improved design methodology of the $U B C 97$ compared to its 1982 counterpart. The second key observation is the universal localization of damage in the lower floors of both buildings that could lead to a greater number of stories pancaking on top of each other if a single story were to give way, resulting in progressive collapse of the building. But perhaps the most important finding is that peak interstory drifts in the existing building exceed 0.10 in most parts of the San Fernando Valley, and in many regions of the Los Angeles Basin (Santa Monica, West Los Angeles, El Segundo, Compton, Norwalk, Downey, Seal Beach, Fullerton, Santa Ana, Baldwin Park, La Puente, Monrovia, and Alhambra), a value which is indicative of 
probable collapse. In Hollywood, Beverly Hills, and downtown Los Angeles, the existing building model experiences peak drifts of $0.04-0.06$, which is at or above the FEMA Collapse Prevention performance level.

The redesigned building model experiences peak drifts of 0.10 (the probable threshold for collapse) or greater in the western half of the San Fernando Valley. The eastern half experiences peak drifts of over 0.06, thus exceeding the Collapse Prevention performance criteria under FEMA guidelines. Progressing north to south into the Los Angeles Basin, note that the peak drifts in the redesigned building model are in the range of $0.04-0.06$, just satisfying the FEMA Collapse Prevention level. These drifts are indicative of serious damage, warranting building closures and business interruption. It should be mentioned, however, that the primary goal of the building code is to prevent collapse of buildings in such large events, and in this regard the UBC 97 is partly successful (although some of the failure modes not included in the modeling could indicate greater damage than estimated here). The percentage of connections that fractures in the existing building model at each of the analysis sites is illustrated on a map in Figure 9c. Here the two segments of the elastofiber element that is used to model each moment-frame beam or column are considered as connections. Since there are 355 elastofiber elements representing the moment-frame beams and columns of the existing building, the total number of connections is taken to be 710 . The vast percentage of connections that fracture in the existing building model throughout southern California is disconcerting.

Plotted in Figures 10a and 10b are the magnitude and direction of the permanent offset of the existing and redesigned building models, respectively, at the penthouse level following the earthquake. This permanent offset is a result of the irrecoverable plastic deformation in the structural components-beams, columns, and joints. A building leaning in such a fashion would lead to scores of problems. As an example, the 6-in. tilt in the Woodland Hills building following the Northridge earthquake led to misalignment in the elevators. Bringing the building back to plumb would inevitably result in closure and significant direct and indirect costs. The length of the arrows in the figures is proportional to the tilt magnitude. The scale is saturated at $1.5 \mathrm{~m}$, which corresponds roughly to an average inclination of $2 \%$ over the height of the buildings. At this inclination P- $\Delta$ effects during shaking from aftershocks could be quite severe on the buildings, jeopardizing their stability.

For eight representative sites out of the set of 636 (geographically uniformly distributed in southern California), detailed results of building performance are given in an online report (Krishnan et al. 2005). These sites are located in Thousand Oaks, Northridge, West Los Angeles, downtown Los Angeles, Baldwin Park, Anaheim, Long Beach, and Santa Ana. Movies of the rupture of the San Andreas Fault and the propagation of the seismic waves into the San Fernando Valley and the Los Angeles Basin and beyond, and the shaking of the existing and new building models under these motions at these representative sites in southern California can be seen at http:// www.ce.caltech.edu/krishnan. Out of these eight sites, the existing building model is seen collapsing in Thousand Oaks and Northridge. Included in the report are snapshots of building deformation immediately following the earthquake, time histories of the three components of ground velocity and displacement (bandpass-filtered between $2 \mathrm{~s}$ 

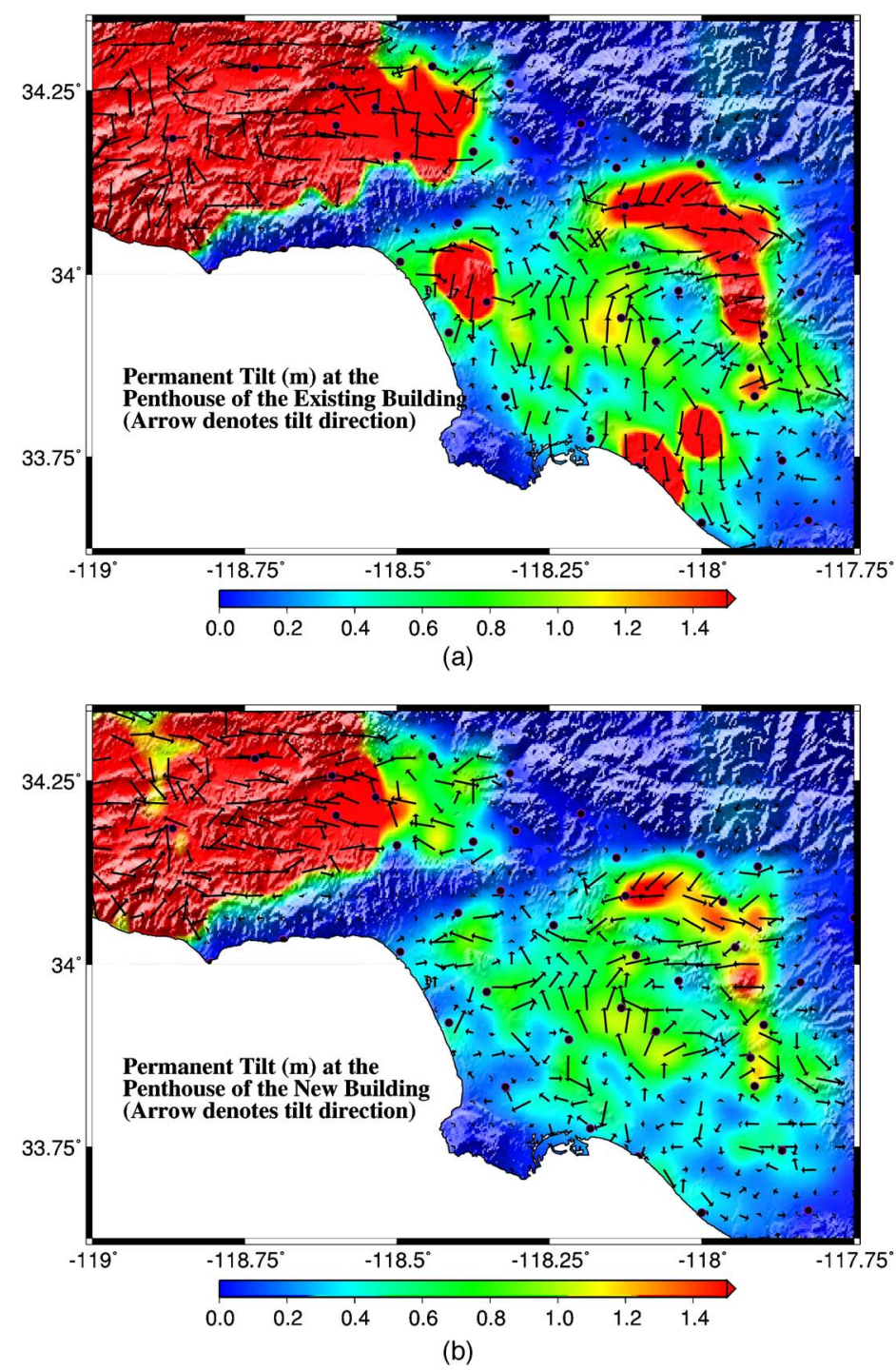

Figure 10. Permanent offset at the penthouse level in the existing (a) and redesigned (b) buildings for a hypothetical $\mathrm{M}_{\mathrm{w}} 7.9$ earthquake (north-to-south rupture) on the San Andreas Fault.

and 1,000 s), time histories of the east and north components of the penthouse displacements of the existing and redesigned building models, tables detailing the performance of the structural components (plastic rotation in beams, columns, and panel zones), bar diagrams illustrating the peak interstory drifts over the height of the two building models, maps of plastic rotation in beams, columns, and panel zones, and finally, maps of fracture locations in the moment frames of the existing building. In this article, some details of the response of the two buildings at the Northridge site are presented. Figure 

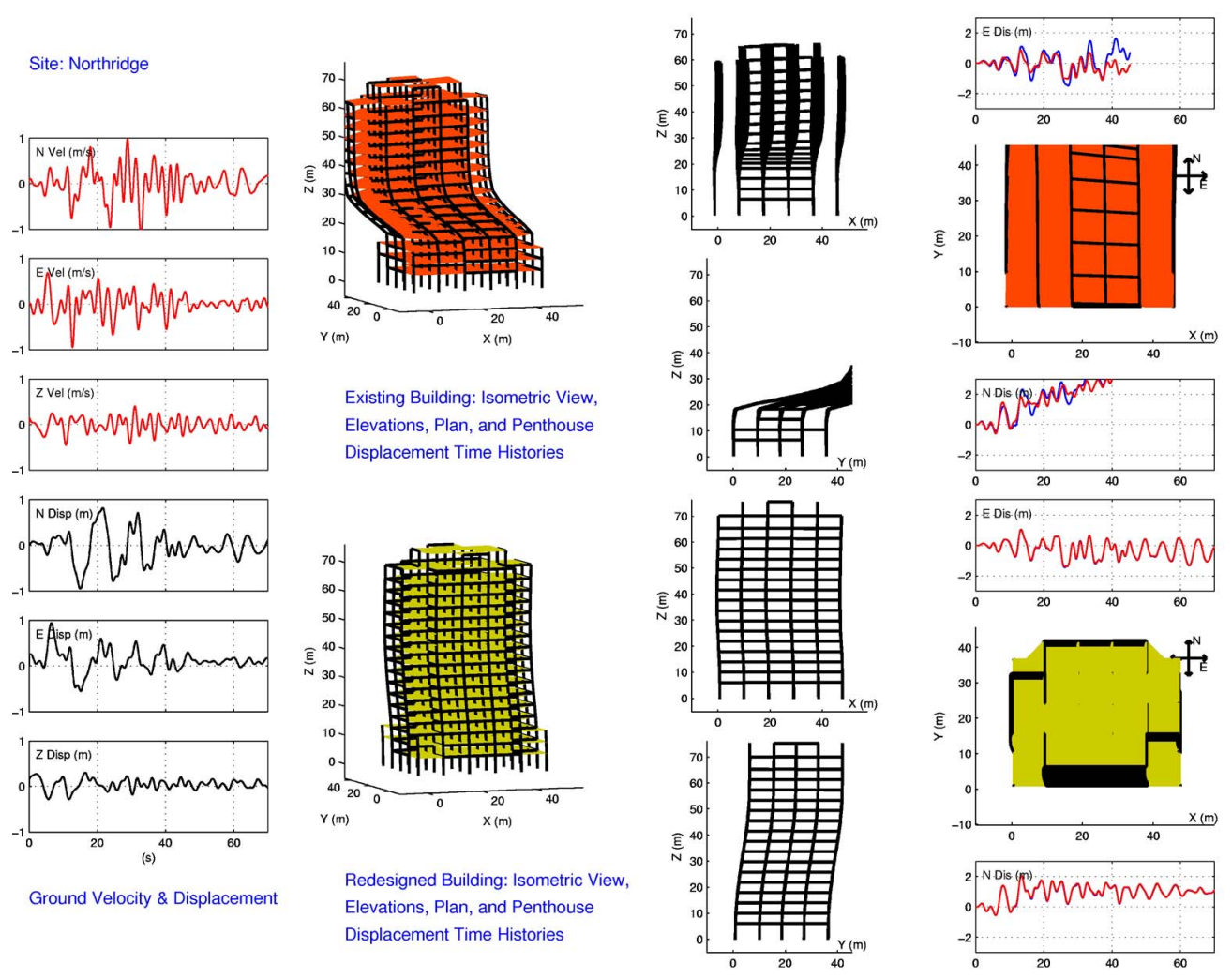

Figure 11. Snapshot of building deformation (scaled up by a factor of 5) immediately following the earthquake at the Northridge analysis site for a hypothetical $\mathrm{M}_{\mathrm{w}} 7.9$ earthquake (northto-south rupture) on the San Andreas Fault. Also shown are the time histories of the three components of the ground velocity and displacement (bandpass-filtered between $2 \mathrm{~s}$ and 1,000 s using a Butterworth filter), and the east and north components of the penthouse displacement of the existing and redesigned building models.

11 shows a snapshot of the deformed shapes of the two buildings following the earthquake. The existing building collapses in this instance with failure occurring in stories 5-9. Shown in this figure are the three components of ground velocity and displacement at Northridge (bandpass-filtered between $2 \mathrm{~s}$ and 1,000 s), and the east and north components of the roof displacements of the two buildings. Along with the isometric view of the two buildings, their deformed elevation and plan views are also illustrated. The redesigned building stays up but develops a significant kink, leading to a permanent roof tilt of about $1 \mathrm{~m}$ to the north. The peak drifts over the height of the two buildings are illustrated in Figure 12.

Note that the results of the north-to-south rupture could be quite different for other slip distributions, for example, slip rising quickly to a peak value and then gradually 


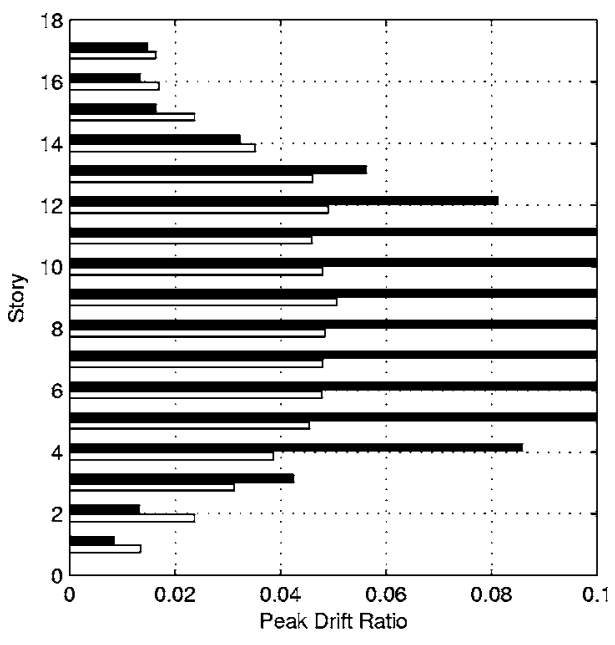

(a)

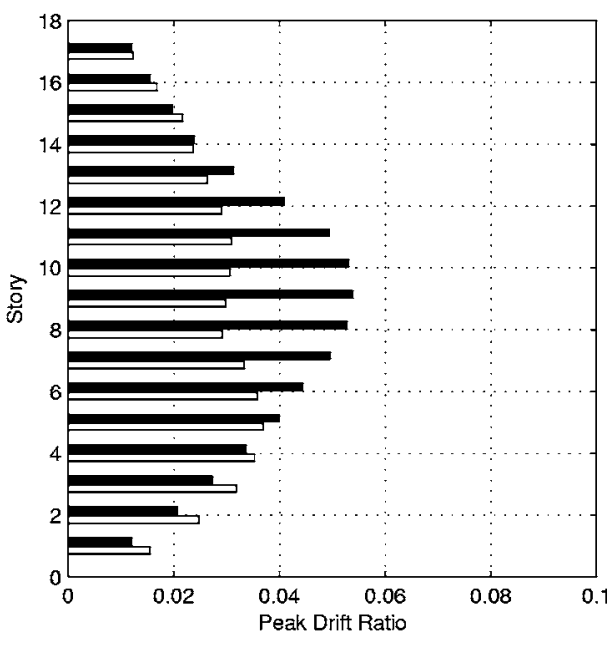

(b)

Figure 12. Peak east-west/X (white bars) and north-south/Y(black bars) drifts in each story of the existing (a) and redesigned (b) building models at the Northridge analysis site. The drift scale is saturated at 0.10 .

dropping off as in the 1857 earthquake. Directivity also plays a critical role, as seen in a south-to-north rupture simulation of the same earthquake described in the next section.

\section{SAN ANDREAS SIMULATION: SOUTH-TO-NORTH RUPTURE}

The second scenario investigated in this study involves the rupture of the same segment of the San Andreas Fault except that it proceeds from south to north instead of the other way around (with the largest amount of slip occurring further north in central California). Ground shaking is far less severe in this scenario, as shown in Figure 13. This demonstrates the effects of directivity and of the slip distribution in dictating the level of ground shaking and the associated damage in buildings. While the San Fernando Valley, with peak velocities and displacements of $0.6 \mathrm{~m} . \mathrm{s}^{-1}$ and $0.6 \mathrm{~m}$, respectively, still experiences the most shaking, Santa Monica, El Segundo, and to some extent Baldwin Park with peak velocities of $0.5 \mathrm{~m} . \mathrm{s}^{-1}$ and peak displacements of $0.5 \mathrm{~m}$ also experience a similar intensity of ground motion. Peak velocities and displacements are in the neighborhood of $0.3 \mathrm{~m} \cdot \mathrm{s}^{-1}$ and $0.4 \mathrm{~m}$, respectively, in the remaining parts of Los Angeles and Orange counties.

The reduced level of shaking is reflected in the results of the building analyses. The peak drifts in the two building models are in the range of $0.02-0.04$, indicating that there is no significant danger of collapse. However, damage is still significant enough to warrant building closures and compromise life safety in some instances. As in the case of the north-to-south rupture scenario, the peak interstory drifts in the middle third and bottom third of the existing building are greater than in the top third, which indicates that 


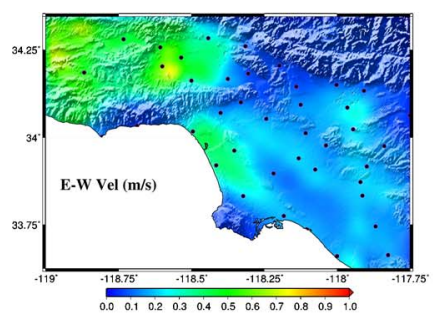

(a)

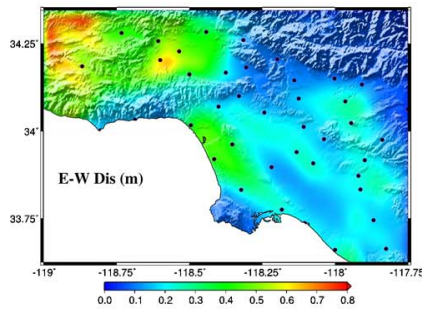

(b)

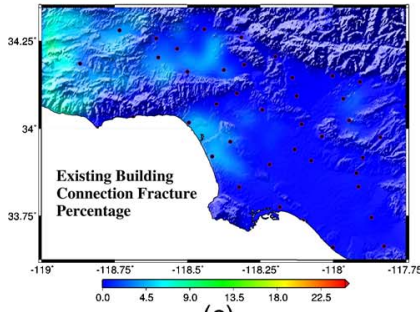

(c)

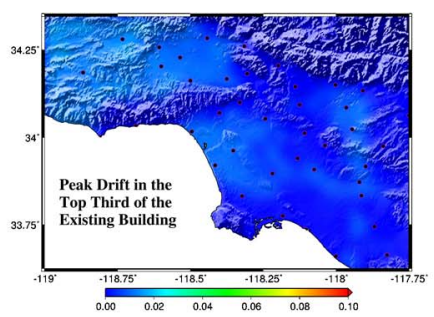

(d)

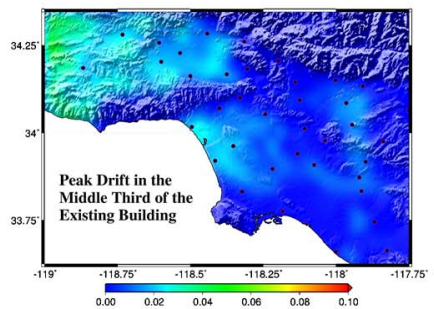

$(e)$

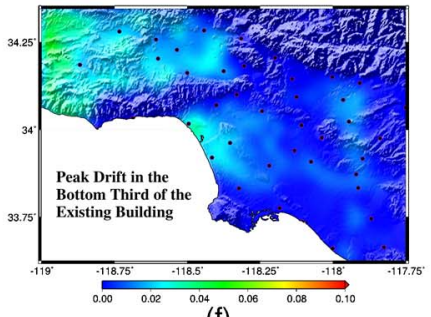

(f)

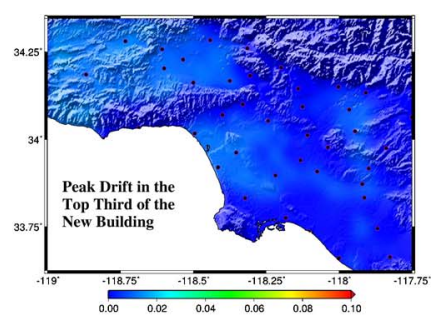

(g)

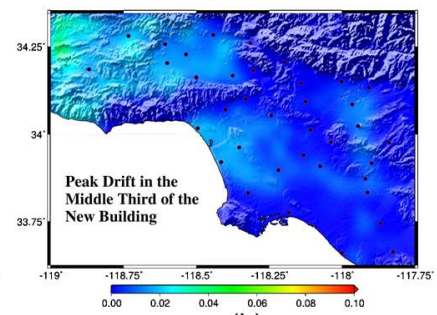

(h)

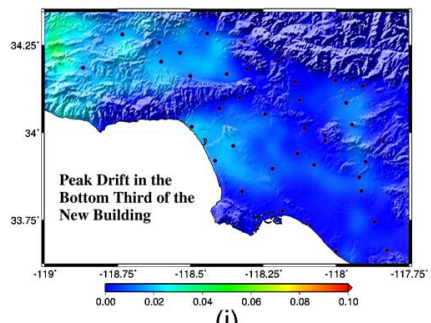

(i)

Figure 13. Ground shaking and building performance for a hypothetical $\mathrm{M}_{\mathrm{w}} 7.9$ earthquake (south-to-north rupture) on the San Andreas Fault: Shown are the peak ground velocity (a) and displacement (b) of synthetic seismograms lowpass-filtered using a Butterworth filter with a corner period of $2 \mathrm{~s}$, (c) the percentage of connections in the existing building where fractures occur (out of 710 connections with the two ends of each moment-frame beam and column defined as connections), the peak interstory drift in the top (d), middle (e), and bottom third (f) of the existing building, and the corresponding peak drifts for the new building ( $\mathrm{g}, \mathrm{h}$, and i, respectively). The peak drifts in existing and new buildings are in the range of $0.02-0.04$, indicating that there is no significant danger of collapse. However, damage would still be significant enough to warrant building closures and compromise life safety in some instances.

the damage is localized in the lower floors. The redesigned building once again outperforms the existing building throughout the region, although by a smaller margin than for the north-to-south rupture scenario.

\section{CONCLUDING REMARKS}

From geologic evidence it is inevitable that a large earthquake will occur on the San Andreas Fault sooner or later. Ground-motion simulations indicate that, depending on the rupture initiation location, propagation direction, and the slip distribution, the San 
Fernando Valley and the Los Angeles Basin could experience severe shaking (with peak velocities and displacements in the $1-2 \mathrm{~m} \cdot \mathrm{s}^{-1}$ and $1-2 \mathrm{~m}$ ranges, respectively). Analysis of an existing 18-story steel moment-frame building model placed at various locations in southern California indicates probable collapse or very serious damage during at least one of the two scenarios. The permanent tilt in the building is quite large at many geographical locations, and P- $\Delta$ effects could jeopardize building stability during shaking from the strong aftershocks that usually follow the main shock. Although the new building, designed according to $U B C$ 97, performs better, damage is still serious enough that its performance cannot be classified as "Life Safe" at many locations in the region. Let us note that these conclusions are based on analyses of two 18-story steel momentframe buildings and cannot be extrapolated to other buildings with different function, geometric configuration, materials, or structural systems.

The main purpose of this paper is to illustrate how seismic hazard assessment can be made much more quantitative by considering realistic rupture scenarios on nearby faults and subjecting specific engineered structures to the resulting ground motions. We have illustrated that the details of a rupture scenario can have a profound effect on the resulting ground motion, and that the rupture direction, i.e., the directivity, plays a critical role. Therefore, we envision a much more quantitative approach to seismic hazard assessment in which one constructs a detailed 3-D numerical model of an engineered structure, e.g., steel-frame or reinforced-concrete buildings, highway overpasses, dams, pipelines, etc., and subjects this particular engineered structure to a wide variety of geologically and geophysically plausible ground motions generated by earthquakes on nearby faults. The results of this collection of scenario simulations can then be used to make well-informed engineering decisions about how to improve the ability of the structure to withstand plausible strong ground motions. Of course, the band-limited nature of the simulated ground motion needs to be taken into account and the validity of using these waveforms for the specific structure under consideration needs to be ascertained. In this paper we provide a proof-of-concept for two specific steel-frame buildings subjected to two plausible earthquakes on the San Andreas Fault. From a practical perspective, if one wanted to construct a particular building in, say, downtown Los Angeles, these would be just two of a much broader range of scenario earthquakes on a number of faults to which one would subject the engineered structure of interest. Although the analysis in this paper illustrates the simulation of the physical phenomena of earthquakes and building damage alone, human injuries and deaths as well as economic and financial losses could be part of more complete end-to-end simulations. Finally, for future studies such as this, two areas of research need attention: including the top soil layer in the Earth models and soil-structure interaction in the analyses of the structure.

\section{ACKNOWLEDGMENTS}

We wish to thank John F. Hall, Thomas Heaton, and Hiroo Kanamori of the California Institute of Technology for their input during the course of this study, and the Earthquake Spectra editor and reviewers for valuable comments that enhanced the article. The numerical simulations were performed on the Division of Geological \& Planetary Sci- 
ences Dell cluster at the California Institute of Technology and the Seawulf cluster at the University of Toronto.

\section{REFERENCES}

Agnew, D. C., and Sieh, K., 1978. A documentary study of the felt effects of the great California earthquake of 1857, Bull. Seismol. Soc. Am. 68 (6), 1717-1729.

American Society of Civil Engineers (ASCE), 2000. Prestandard and Commentary for the Seismic Rehabilitation of Buildings, prepared for the SAC Joint Venture, published by the Federal Emergency Management Agency, FEMA-356, Washington, D.C.

Anderson, J. G., Lee, Y., Zeng, Y., and Day, S. M., 1996. Control of strong motion by the upper 30 meters, Bull. Seismol. Soc. Am. 86, 1749-1759.

Carlson, A., 1999. Three-dimensional Nonlinear Inelastic Analysis of Steel Moment-Frame Buildings Damaged by Earthquake Excitations, Technical Report EERL 99-02, Earthquake Engineering Research Laboratory, California Institute of Technology, Pasadena, CA.

Clouteau, D., and Aubry, D., 2001. Modifications of the ground motion in dense urban areas, $J$. Comput. Acoust. 9 (4), 1659-1675.

Darragh, R., Cao, T., Graizer, V., Shakal, A., and Huang, M., 1994. Los Angeles Code Instrumented Building Records from the Northridge, California Earthquake of January 17 1994: Processed Release No. 1, Technical Report OSMS 94-17, California Strong Motion Instrumentation Program, California Department of Conservation, Division of Mines and Geology (now California Geological Survey), Sacramento, CA.

El-Tawil, S., and Deierlein, G. G., 1996. Inelastic Dynamic Analysis of Mixed Steel-Concrete Space Frames, Technical Report Structural Engineering 96-05, Cornell University, Ithaca, NY.

Fenves, G. L., and Serino, G., 1990. Soil-structure interaction in buildings from earthquake records, Earthquake Spectra 6 (4), 641-655.

Filippou, F., and Romero, M. L., 1998. Nonlinear and dynamic analysis from research to practice, in N. K. Srivatsava (editor), Structural Engineering World Wide 1998, pp. T101-3. Elsevier Science Ltd., New York.

Graves, R. W., 1998. Three-dimensional finite-difference modeling of the San Andreas Fault: Source parameterization and ground-motion levels, Bull. Seismol. Soc. Am. 88 (4), 881-897.

Hall, J. F., 1998. Seismic response of steel frame buildings to near-source ground motions, Earthquake Eng. Struct. Dyn. 27, 1445-1464.

Hall, J., Heaton, T., Halling, M., and Wald, D., 1995. Near-source ground motion and its effects on flexible buildings, Earthquake Spectra 11 (4), 569-605.

Haskell, N. A., 1960. Crustal reflection of plane SH waves, J. Geophys. Res. 4147-4150.

Heaton, T., Hall, J., Wald, D., and Halling, M., 1995. Response of high-rise and base-isolated buildings to a hypothetical $\mathrm{M}_{\mathrm{w}} 7.0$ blind thrust earthquake, Science 267, 206-211.

International Conference of Building Officials (ICBO), 1982. 1982 Uniform Building Code, Volume 2, Whittier, CA.

— 1997. 1997 Uniform Building Code, Volume 2, Whittier, CA.

Ji, C., Tan, Y., Helmberger, D., and Tromp, J., 2003. Modeling teleseismic P and SH static offsets for great strike-slip earthquakes, in Proceedings of the American Geophysical Union Fall Meeting. 
Kohler, M., Magistrale, H., and Clayton, R., 2003. Mantle heterogeneities and the SCEC threedimensional seismic velocity model version 3, Bull. Seismol. Soc. Am. 93, 757-774.

Komatitsch, D., and Tromp, J., 1999. Introduction to the spectral element method for threedimensional seismic wave propagation, Geophys. J. Int. 139, 806-822.

Komatitsch, D., Liu, Q., Tromp, J., Süss, P., Stidham, C., and Shaw, J. H., 2004. Simulations of ground motion in the Los Angeles Basin based upon the spectral element method, Bull. Seismol. Soc. Am. 94, 187-206.

Krishnan, S., 2003a. FRAME3D-A Program for Three-dimensional Nonlinear Time-History Analysis of Steel Buildings: User Guide, Technical Report EERL 2003-03, Earthquake Engineering Research Laboratory, California Institute of Technology, Pasadena, CA.

Krishnan, S., 2003b. Three-dimensional Nonlinear Analysis of Tall Irregular Steel Buildings Subject to Strong Ground Motion, Technical Report EERL 2003-01, Earthquake Engineering Research Laboratory, California Institute of Technology, Pasadena, CA.

Krishnan, S., Ji, C., Komatitsch, D., and Tromp, J., 2005. Performance of 18-story Steel Moment-Frame Buildings during a Large San Andreas Earthquake-A Southern Californiawide End-to-end Simulation, Technical Report EERL 2005-01, Earthquake Engineering Research Laboratory, California Institute of Technology, Pasadena, CA.

Krishnan, S., and Hall, J. F., 2006a. Modeling steel frame buildings in three dimensions_-Part I: Panel zone and plastic hinge beam elements, J. Eng. Mech. 132 (4), 345-358.

Krishnan, S., and Hall, J. F., 2006b. Modeling steel frame buildings in three dimensions-Part II: Elastofiber beam element and examples, J. Eng. Mech. 132 (4), 359-374.

Kunnath, S. K., 1995. Enhancements to Program IDARC: Modeling Inelastic Behavior of Welded Connections in Steel Moment-Resisting Frames, Technical Report NIST GCR 95673, Building and Fire Research Laboratory, National Institute of Standards and Technology, Gaithersburg, MD.

Liu, Q., Polet, J., Komatitsch, D., and Tromp, J., 2004. Spectral-element moment tensor inversions for earthquakes in southern California, Bull. Seismol. Soc. Am. 94 (5), 1748-1761.

Lobo, R., 1994. IDARC3D: Inelastic Damage Analysis of Reinforced Concrete Structures in Three Dimensions, Technical report, National Center for Earthquake Engineering Research, University at Buffalo, State University of New York, Buffalo.

Lobo, R. F., Skokan, M. J., Huang, S. C., and Hart, G. C., 1998. Three-dimensional analysis of a 13-story steel building with weld connection damage, in N. K. Srivatsava (editor), Structural Engineering World Wide 1998, pp. T114-2, Elsevier Science Ltd., New York.

Magistrale, H., McLaughlin, K., and Day, S., 1996. A geology based 3-D velocity model of the Los Angeles Basin sediments, Bull. Seismol. Soc. Am. 86, 1161-1166.

Magistrale, H., Day, S., Clayton, R., and Graves, R., 2000. The SCEC southern California reference three-dimensional seismic velocity model version 2, Bull. Seismol. Soc. Am. 90 (6B), S65-S76.

Mazzoni, S., McKenna, F., and Fenves, G. L., 2005. OpenSees Command Language Manual, Pacific Earthquake Engineering Research (PEER) Center, University of California, Berkeley. http://opensees.berkeley.edu

Meltzner, A. J., and Wald, D. J., 1998. Foreshocks and Aftershocks of the Great 1857 California Earthquake, USGS Open-File Rep. 98-465, Pasadena, CA.

Olsen, K. B., Archuleta, R. J., and Matarese, J. R., 1995. Three dimensional simulation of a magnitude 7.75 earthquake on the San Andreas Fault, Science 270, 1628-1632. 
Powell, G. H., and Campbell, S., 1994. DRAIN-3DX Element Description and User Guide for Element Type01, Type05, Type08, Type09, Type15, and Type17, Technical Report UCB/ SEMM-94/08, Structural Engineering Mechanics and Materials, University of California, Berkeley.

Prakash, V., Powell, G. H., and Campbell, S., 1994. DRAIN-3DX Base Program Description and User Guide, Version 1.10, Technical Report UCB/SEMM-94/07, Structural Engineering Mechanics and Materials, University of California, Berkeley.

SAC Joint Venture, 1995a. Analytical and Field Investigations of Buildings Affected by the Northridge Earthquake of January 17, 1994-Part 1, Technical Report SAC 95-04, Part 1, Structural Engineers Association of California, Applied Technology Council, and California Universities for Research in Earthquake Engineering.

- 1995b. Analytical and Field Investigations of Buildings Affected by the Northridge Earthquake of January 17, 1994-Part 2, Technical Report SAC 95-04, Part 2, Structural Engineers Association of California, Applied Technology Council, and California Universities for Research in Earthquake Engineering.

, 1995c. Surveys and Assessments of Damage to Buildings Affected by the Northridge Earthquake of January 17, 1994, Technical Report SAC 95-06, Structural Engineers Association of California, Applied Technology Council, and California Universities for Research in Earthquake Engineering.

_ 2000a. Recommended Seismic Design Criteria for New Steel Moment-Frame Buildings, prepared for the Federal Emergency Management Agency, FEMA-350, Washington, D.C.

- 2000b. Recommended Specifications and Quality Assurance Guidelines for Steel Moment-Frame Construction for Seismic Applications, prepared for the Federal Emergency Management Agency, FEMA-353, Washington, D.C.

Serino, G., 1989. Dynamic Soil-Structure Interaction in Building Response from Earthquake Records, Technical Report UCB/SEMM-1989/01, Department of Civil Engineering, University of California, Berkeley.

Sieh, K. E., 1978. Slip along the San Andreas Fault associated with the great 1857 earthquake, Bull. Seismol. Soc. Am. 68 (5), 1421-1448.

Stewart, J. P., Seed, R. B., and Fenves, G. L., 1998. Empirical Evaluation of Inertial SoilStructure Interaction Effects, Technical Report PEER-98/07, Pacific Earthquake Engineering Center, University of California, Berkeley.

Süss, M. P., and Shaw, J. H., 2003. P-wave seismic velocity structure derived from sonic logs and industry reflection data in the Los Angeles Basin, J. Geophys. Res. 108 (B3) Article no. 2170 .

Trifunac, M., Todorovska, M., and Hao, T., 2001a. Full-scale experimental studies of soilstructure interaction-A review, in Proceedings of the Second U. S.-Japan Workshop on SoilStructure Interaction, Tsukuba City, Japan, 52 pp. (CD-ROM).

Trifunac, M., Hao, T., and Todorovska, M., 2001b. Response of a 14-story Reinforced Concrete Structure to Nine Earthquakes: 61 Years of Observation in the Hollywood Storage Building, Technical Report CE 01-02, Department of Civil Engineering, University of Southern California, Los Angeles.

Weldon, R. J., Fumal, T. E., Biasi, G. P., and Scharer, K. M., 2005. Past and future earthquakes on the San Andreas Fault, Science 308, 966-967.

(Received 5 August 2005; accepted 10 February 2006) 